\title{
Inflation puzzles, the Phillips Curve and output expectations: new perspectives from the Euro Zone
}

\author{
Giuliana Passamani $^{1} \cdot$ Alessandro Sardone $^{2} \cdot$ Roberto Tamborini $^{1}{ }^{10}$
}

Accepted: 18 June 2021 / Published online: 15 July 2021

(c) The Author(s) 2021

\begin{abstract}
Confidence in the Phillips Curve (PC) as predictor of inflation developments along the business cycle has been shaken by recent "inflation puzzles" in advanced countries, such as the "missing disinflation" in the aftermath of the Great Recession and the "missing inflation" in the years of recovery, to which the Euro-Zone "excess deflation" during the post-crisis depression may be added. This paper proposes a newly specified Phillips Curve model, in which expected inflation, instead of being treated as an exogenous explanatory variable of actual inflation, is endogenized. The idea is simply that if the $\mathrm{PC}$ is used to foresee inflation, then its expectational component should in some way be the result of agents using the PC itself. As a consequence, the truly independent explanatory variables of inflation turn out to be the output gaps and the related forecast errors by agents, with notable empirical consequences. The model is tested with the Euro-Zone data 1999-2019 showing that it may provide a consistent explanation of the "inflation puzzles" by disentangling the structural component from the expectational effects of the PC.
\end{abstract}

Keywords Phillips curve $\cdot$ Inflation puzzles $\cdot$ Output forecasts

JEL Classification D84 $\cdot$ E24 $\cdot$ E32 $\cdot$ E52

Responsible Editor: Fritz Breuss.

Roberto Tamborini

roberto.tamborini@unitn.it

Giuliana Passamani

giuliana.passamani@unitn.it

Alessandro Sardone

alessandro.sardone@iwh-halle.de

1 Department of Economics and Management, University of Trento, Trento, Italy

2 Halle Institute for Economic Research (IWH), Halle, Germany 


\section{Introduction}

The Great Recession of 2008-2009 represents a watershed for macroeconomics. Kernel relationships broke down, thus showing fragility of macroeconomic models and their inability to make accurate predictions. The price Phillips Curve (PC), which describes the relationship between inflation and the cyclical position of economic activity (we shall refer to this format of the PC unless otherwise stated), is on the forefront. Its failure to produce reliable forecasts of future price developments, has led many scholars to consider this instrument in need of substantial revisions. ${ }^{1}$

A brief account of the recent empirical "puzzles" of the PC may start from the evidence of its "flattening" during the Great Moderation era put forward by Blanchard et al. (2015) who reported two widely shared stylized facts. First, the substantial reduction of the structural slope of the PC plummeting from more than 1 in the mid-1970s to about 0.3. Second, the "anchoring of expectations", meaning that the expectational component of inflation had become more stable and tighter (less weight of lagged inflation rates), implying that both expected and actual inflation would tend to converge faster towards the official inflation target.

These features seemed to persist in the aftermath of the Great Recession, when the "missing deflation puzzle" emerged in the US, where the collapse of about $10 \%$ of GDP relative to trend was followed by a modest decline of $1.5 \%$ of inflation (Williams 2010). In the Euro Zone (EZ), however, concerns at the European Central Bank (ECB) and among scholars were of opposite sign: a deflationary drift with de-anchoring of expectations seemed under way (Draghi 2014, 2016). Research on the post-crisis EZ challenged the consensus on the worldwide flattening of the PC pointing to its "steepening" (e.g. Riggi and Venditti 2014, 2015; Oinonen and Paloviita 2014; Bank of Ireland 2014). Direct investigation of expectation forecasts showed both their downward drift and a significant underestimation of actual inflation (Riggi and Venditti 2014; Miccoli and Neri 2015). Parallelly, direct evidence of the downward de-anchoring of expectations was detected in various studies (Buono and Formai 2016; Fracasso and Probo 2017; Nautz 2017; Natoli and Sigalotti 2017).

Afterwards, since recovery was taking hold across advanced economies, the new "missing inflation puzzle" spurred researchers' efforts as inflation remained subdued in spite of more sustained economic activity, falling unemployment and some recovery of wage dynamics. In that period, the EZ realigned with the rest of the advanced world (Ciccarelli and Osbat 2017; Fiedler et al. 2018; Bobeica and Sokol 2019).

Given the intrinsic relationship between accurate economic forecasts and the implementation of appropriate economic policies, the literature about revisions of the PC has taken two main avenues (Ehrmann et al. 2020). One is, as it were, more radical, arguing for a dismissal of the traditional macro-apparatus in favor of a revival of a micro, disaggregated approach to the unemployment-wages-prices transmission. The other remains within the macro-tradition seeking for better

\footnotetext{
1 See for instance Hall and Sargent (2018) and the papers collected at the European Central Bank Conference "Inflation in a changing environment", Frankfurt, September 23-24, 2019. A survey of the conference is provided by Ehrmann et al. (2020).
} 
specifications of the PC estimation equation. Our contribution may be ascribed to this latter strand.

In particular, we locate the need for better specification of the PC in its expectational component. For instance, Coibion and Gorodnichenko (2015) show that the missing deflation puzzle in the US in the aftermath of the Great Recession can be solved by replacing the usual surveys of expert forecasts with households' ones, as the latter better captured the impact on consumer prices of the concomitant upsurge of oil and commodity prices. Jörgensen and Lansing (2019) follow the literature about boundedly-rational formation of expectations, and assume that agents update their inflation expectations upon solving a signal extraction problem to disentangle temporary versus permanent shocks to inflation. They show that the slope of the PC may appear flatter or stepper depending on the evolution of the parameter (the Kalman-filter gain) that governs the expectation formation process. We approach the issue from a more general perspective.

Inflation expectations expressed "on the right-hand-side" of the PC are generally treated as independent variables, collected from various available forecast surveys. This practice is not satisfactory for two reasons. First, the PC should be understood as one component of a set of co-evolving macroeconomic relationships (think for instance of the New Keynesian three-equation model). Indeed, to the extent that the central bank controls inflation tightly, it is no surprise that the ex-post inflationoutput relationship is seemingly flat (Bernanke 2007). Second, and consequently, the alleged explanatory variables in the PC are co-determined elsewhere in the system, and may not even be independent one of another. This is specifically the case of inflation expectations, which are arguably elaborated, in some way and to some extent, according to the evolution of the macroeconomics.

It may be said that major institutions indeed base their inflation forecasts (also) on full-blown macro-models. Nonetheless, the $\mathrm{PC}$ as a stand-alone equation remains a pivotal macroeconomic tool as testified by the debate summarized above. More importantly, several studies show that the inflation forecasts collected in available surveys are consistently explained by means of a standard formulation of the PC (Fendel et al. 2011; Rülke 2012; Draeger et al. 2016; Casey 2020). Therefore, in Sect. 2 we present a modified PC where inflation expectations are no longer considered to be independent of the slack variable (output gap in the specific case). ${ }^{2}$ The idea is simply that if the PC is used worldwide to foresee inflation, then its expectational component should in some way be the result of agents using the PC itself. ${ }^{3}$ As a consequence, the independent explanatory variables of inflation turn out to be the output gaps and the related forecast errors by agents, with notable consequences from an empirical point of view. First, standard empirical models with exogenous

\footnotetext{
${ }^{2}$ Similarly, Hazell et al. (2020) develop a regional model for the US economy, in which inflation expectations are assumed to comove with unemployment gap. By iterating expectations forward, they define rational inflation expectation as a function of an expectational "permanent component of the variation in unemployment" (see Hazell et al. 2020, 8), as we do in Eq. (4). Although they differ in the modeling approach employed, they still arrive at similar conclusions to ours.

${ }^{3}$ This idea is consistent with the notion of rational expectations in the sense of agents' learned understanding of the data generation process (Evans and Honkapohja 2011; Kurz 2011).
} 
inflation expectations yield a distorted estimator of the output structural parameter. Second, the observed inflation-output relationship may appear flatter or steeper not (only) owing to structural factors, but (also) to the effect of output expectations and forecast errors. Third, our model allows to disentangle the true output component of inflation from the transitional expectational one. These features relate our model also to the issue of the anchoring (de-anchoring) of expectations, namely anchored (de-anchored) expectations may make the PC seemingly flatter (steeper) in recession and steeper (flatter) in recovery. ${ }^{4}$

Section 3 will provide an empirical application of our model developed on data collected in the EZ from 1999 to 2019. The ECB Survey of Professional Forecasters is employed as proxy of output expectations. Then, an econometric linear regression model is introduced and tested through the ordinary least squares (OLS) method and the generalized method of moments (GMM). Specific tests are provided in support of this choice. Our results show that in the EZ the output component on inflation is not so flat, and the extent to which the post-crisis deflationary drift and the post-recovery missing inflation can be explained by the transitory expectational component.

The last section concludes with a view to new perspectives in terms of empirical research and possible implications regarding monetary and fiscal policies undertaken by public institutions.

\section{The Phillips Curve with endogenous expectations}

A baseline specification of the PC for empirical analysis may be the following (see e.g. Hooper et al. 2019):

$$
\pi_{t}=\alpha+\beta_{1} \pi_{t}^{e}+\beta_{2} x_{t}+\beta_{3} \Lambda(\pi, n)+\beta_{4}^{\prime} Z_{t}+u_{\pi t}
$$

where $\pi_{t}$ is current inflation, $\pi_{t}^{e}$ is an expectational term as of time $t$ to be specified, $x_{t}$ is a measure of the business cycle or "economic slack", $\Lambda(\pi, n)$ is the lag operator of inflation of order $n, Z_{t}$ is a vector of other variables, and $u_{\pi t}$ is a random shock. The intercept $\alpha$ may capture an autonomous drift in inflation.

The empirical issues about the PC revolve around the estimation of coefficient $\beta_{2}$, which is meant to capture the structural slope of the PC, or better the responsiveness of inflation to the business cycle. As to the relevant variable $x_{t}$, it is now common to employ the output gap, defined as the percent difference between actual output (GDP) and the maximum potential output the economy can produce (potential GDP). Looking back at the origins, some would rather use the unemployment gap, the difference between the unemployment rate and the natural rate or the NAIRU, or the Phillips'

\footnotetext{
4 The perceived flattening of the Phillips curve has also generated a good deal of research into the question of why this has happened. The most prevalent explanation is that inflation expectations have become more important (than lagged inflation) as a determinant of current inflation and have become more firmly anchored as the Fed has more clearly committed to achieving a now stated inflation objective of $2 \%$ (p. 6 Hooper et al. 2019).
} 
wage PC altogether where the dependent variable is wage inflation. Researchers testing these respecifications of the PC argue that the puzzles of the price PC are less compelling or vanish altogether (Hooper et al. 2019; Nickel et al. 2019).

More radical revisions of the estimation model wish to capture nonlinearities, that is different reactions of inflation to upward or downward phases of the business cycle (Nalewaik 2016; Lindé and Trabandt 2019; Hooper et al. 2019).

In the following we shall concentrate on the expectational term $\pi_{t}^{e}$ of Eq. 1 . By way of this term, the model accommodates the Monetarist critique to the older Keynesian PC, and is also akin to the (inverted) Lucas (1973) "surprise" aggregate supply. The debate on the nature of the expectational term is, however, still open. In the "accelerationist" PC, Friedman (1968) used adaptive expectations formed on the basis of the last-period inflation term. In the Lucas supply curve (1973) it was replaced by the expectation of current inflation. In the New Keynesian, Calvo-type PC there appears the current expectation of next period inflation. The "hybrid" PC proposed by Galì and Gertler (1999), and adopted for example by Blanchard et al. (2015), splits expectations in a forward-looking component (usually the anticipation of the current inflation) and in a complementary backwardlooking one (usually the previous-period inflation, not dissimilar to Friedman). This amounts to adding the lagged inflation component $\Lambda(\pi, n)$ in order to allow the model to fit inflation persistence.

Our point is that the expectational term, whatever it is, is generally treated as an independent (exogenous) explanatory variable, proxied by available forecast surveys. This practice is problematic for two reasons. The first is that it isolates the PC from the rest of economy, whereas it should better be understood as co-evolving with the rest of the economy. The consequence can easily be seen, for example, through the New Keynesian three-equation model. If the central bank controls inflation tightly by means of the Taylor Rule, the ex-post PC will seemingly be flat because output fluctuates around its potential due to shocks to the IS curve whereas inflation does not deviate from its target. The second, related, reason is that inflation expectations, too, cannot be taken to be exogenous with respect to the evolution of the rest of the economy, and output in particular. Indeed, if the $\mathrm{PC}$ as a stand-alone tool is to survive, a proper treatment of the expectational term may provide the bridge with "the rest of the economy".

Our proposed treatment in the first place considers the case in which $\pi_{t}^{e}$ is the anticipation of the current inflation, with $x_{t}$ equal to the output gap, the other terms $\Lambda(\pi, n)$ and $Z_{t}$ being dropped, that is

$$
\pi_{t}=\alpha+\beta_{1} \pi_{t}^{e}+\beta_{2} x_{t}+u_{\pi t}
$$

Further ingredients mentioned above may enrich the picture, but at the cost of some complexification which is not strictly necessary, at least at this first stage. If the central bank has an inflation target $\pi^{*}$, this should be consistent with the stochastic equilibrium of the inflation process (2), i.e. $\pi_{t}^{e}=\pi_{t}=\pi^{*}, x_{t}=0$, for $u_{\pi t}=0$. It follows 
that $\pi^{*}=\alpha /\left(1-\beta_{1}\right){ }^{5}$ Therefore, substituting $\alpha=\pi^{*}\left(1-\beta_{1}\right)$, we can rewrite Eq. (2) as

$$
\pi_{t}=\pi^{*}+\beta_{1}\left(\pi_{t}^{e}-\pi^{*}\right)+\beta_{2} x_{t}+u_{\pi t}
$$

Where does the expectation of current inflation come from? Treatment of expectation formation is notoriously controversial, but our idea can simply be put this way. If the PC is used worldwide to foresee inflation, its expectational component should in some way come from agents using the PC itself. This idea is consistent with a broad principle of rationality of expectations (of recurrent and stable processes) as the outcome of informed understanding of how the economy works - or the "data generation process" (Evans and Honkapohja 2011; Kurz 2011). In the limit case of the (unboundedly) rational expectations hypothesis $(\mathrm{REH})^{6}, \pi_{t}^{e}$ should be the statistical expected value of inflation, i.e. $\pi_{t}^{e}=E\left(\pi_{t}\right)$ conditional on Eq. (3) (Woodford 2003, ch.3). Consequently,

$$
E\left(\pi_{t}\right)=\pi^{*}+\frac{\beta_{2}}{1-\beta_{1}} E\left(x_{t}\right)
$$

The PC-based rational expectation of inflation at time $t$ can be expressed as a deviation from the target determined by the expected value of the output gap in $t$. Intuitively, in a price-setters' environment, output expectations may drive economic agents' strategic behavior, so to justify a variation in the price level.

Substituting Eq. (4) in (3), and rearranging terms, we obtain

$$
\pi_{t}=\pi^{*}+\frac{\beta_{2}}{1-\beta_{1}}\left[\beta_{1} E\left(x_{t}\right)+\left(1-\beta_{1}\right) x_{t}\right]+u_{\pi t}
$$

The actual inflation path around the target results to be the linear combination of the expected and the actual output gap, where $\beta_{1}$ represents the weight between the two terms, plus random shocks. It may be noted that Eq. (5) nests two extreme cases. If $\beta_{1}=0$, i.e. no expectational component of inflation, the equation reproduces the old Keynesian PC such that inflation is procyclical, given its structural slope $\beta_{2}$. If $\beta_{1}=1$, i.e. full pass-through of expected inflation, the PC becomes vertical with respect to expected nonzero values of $x_{t}$. In other words, any small expected deviation of output from potential is fully transmitted to inflation. This verticalization of the $\mathrm{PC}$, though, is not necessarily due to full wage-price flexibility $\left(\beta_{2} \rightarrow \infty\right)$, but to the expectational component of inflation.

Taking a step forward, we can express actual and expected output gaps in terms of forecast errors or Lucas's "surprises"

\footnotetext{
${ }_{5}$ An autonomous inflation drift $\alpha>0$ may explain why the inflation target is generally positive. Driving the drift to zero would require a permanent negative output gap (see also Woodford 2003, ch.3).

${ }^{6}$ The standard REH model solution is now regarded as the limit case of the broader notion of rationality of expectations recalled above once a number of conditions hold regarding agents' learning of the data generation process. Recent examples with regard to the PC are Evans and McGough (2018), GarcíaSchmidt and Woodford (2019), Jörgensen and Lansing (2019).
} 
Table 1 Effects of output gaps and forecast errors on the Phillips Curve, Eq. (7)

\begin{tabular}{lll}
\hline & $v_{t}>0$ & $v_{t}<0$ \\
\hline$x_{t}>0$ & (Underestimated gap) & (Overestimated gap) \\
& Flattening & Steepening \\
$x_{t}<0$ & (Overestimated gap) & (Underestimated \\
& & gap) \\
& Steepening & Flattening \\
\hline
\end{tabular}

$$
v_{t}=x_{t}-E\left(x_{t}\right)
$$

By way of Eq. (6), Eq. (5) can be rewritten as

$$
\pi_{t}=\pi^{*}+\frac{\beta_{2}}{1-\beta_{1}} x_{t}-\frac{\beta_{2} \beta_{1}}{1-\beta_{1}} v_{t}+u_{\pi t}
$$

If the REH holds, forecast errors will be random, with zero mean, and uncorrelated, so that the expected value of (7) coincides with (4).

In the first place, we may employ our inflation equation in connection with the issue of anchoring $v s$. de-anchoring of expectations. In the empirical literature, after Bernanke (2007), the most common criterion used to test the anchoring of expectations is based on their responsiveness to macroeconomic news. Therefore, we may also say that agents with well-anchored expectations hold $E\left(x_{t}\right)=0$ at all times irrespective of the observed news about $x_{t}$. Consequently, $v_{t}=x_{t}$, and

$$
\pi_{t}=\pi^{*}+\beta_{2} x_{t}+u_{\pi t}
$$

By contrast, agents with de-anchored expectations will tend to correlate their output gap expectation to its observed values. In the limit case of fully anticipated output gaps, $v_{t}=0$, the result is:

$$
\pi_{t}=\pi^{*}+\frac{\beta_{2}}{1-\beta_{1}} x_{t}+u_{\pi t}
$$

We can therefore define two macroeconomic regimes depending on the state of expectations in which the PC is different (see also Nalewaik 2016; Gobbi et al. 2018; Hooper et al. 2019). When expectations are anchored (AE regime), Eq. (8) shows a seemingly old Keynesian PC whose estimation would yield the structural slope $\beta_{2}$. When expectations are de-anchored (DE regime), Eq. (9) shows that the PC displays a greater slope, which is not due structural factor $\beta_{2}$ but to the effect of the expectational component $\left(1-\beta_{1}\right)<1$.

Of course, most of the time the economy will lie in between the two pure regimes, so that inflation will be driven by Eq. (7). Consequently, in order to identify the slope of the PC correctly, it is necessary to take into account both the output gap and its forecast errors. Table 1 displays the effects on the PC of the possible combinations of output gaps and forecast errors.

As can be seen, depending on the sign of the forecast error, the PC may appear steeper or flatter. Meaning that the observed change in inflation is greater or smaller 
than due to the output gap alone. This effect is due to forecast errors that shift the PC as in Eq. (7) as a consequence of agents' behavior led by overestimated or underestimated output gaps. The PC appears steeper when output gaps are overestimated $\left(\left|x_{t}\right|<\left|E\left(x_{t}\right)\right|\right)$, in which case forecast errors amplify the effect of output gaps. It appears flatter when output gaps are underestimated $\left(\left|x_{t}\right|>\left|E\left(x_{t}\right)\right|\right)$, in which case forecast errors dampen the effect of output gaps.

The combinations in Table 1 can accommodate the various "puzzles" detected in the empirical literature. For instance, seemingly missing inflation in a boom as well as missing deflation in a slump may be the consequences of the smoothing effect of agents' underestimation of output gaps or better anchored expectations. By contrast, the excess deflation detected in the course of the EZ recession may be the consequence of the amplifying effect of agents' overestimation of negative output gaps. This vindicates the concern at the ECB for the de-anchoring of deflationary expectations running ahead of the actual downward trend of inflation (Draghi 2014, 2016).

\section{Empirical analysis}

In this section we present the results of the econometric tests on our theoretical PC Eq. (7), which lends itself to straightforward treatment in terms of inflation gap, $\pi_{t}-\pi^{*}$. The estimation linear model corresponding to Eq. (7) is as follows:

$$
\inf _{t}=\alpha+\gamma_{1} \text { out }_{t}+\gamma_{2} \text { err }_{t, t-i}+u_{t}
$$

where $\alpha$ is a constant; $\inf _{t}$ represents the gap between actual inflation and inflation targeting (because of the reasons already explained above); out $t_{t}$ is the output gap; $e r r_{t, t-i}$ is the forecast error. The subscript in forecast error term $(t, t-i)$ means that the output gap expectations, used to compute the errors, refer to current time $t$, but are formulated earlier at time $t-i$, with $i=4$ for short-term forecast (1-year), 8 for medium-term forecast (2-years) and 20 for long-term one (5-years). In what follows we will mainly refer to short-term forecast, unless otherwise specified. The error component $u_{t}$ is assumed to be additive. Some specification tests on the residuals will be provided in support of our estimation. ${ }^{7}$

\subsection{The data}

The data have been collected from Eurostat, AMECO, ECB Statistical Data Warehouse and OECD Main Economic Indicators. All the data are quarterly one-year percentage changes referred to the EZ (changing composition up to January 1, 2015) from 1999-Q3 to 2019-Q4.

Inflation data are based on the Harmonized Index of Consumer Price (HICP), from the Eurostat database. The inflation gap is then computed as a simple difference between inflation and $1.9 \%$ inflation target, as the price stability objective of

\footnotetext{
${ }^{7}$ For details and test results, see the "Appendix".
} 


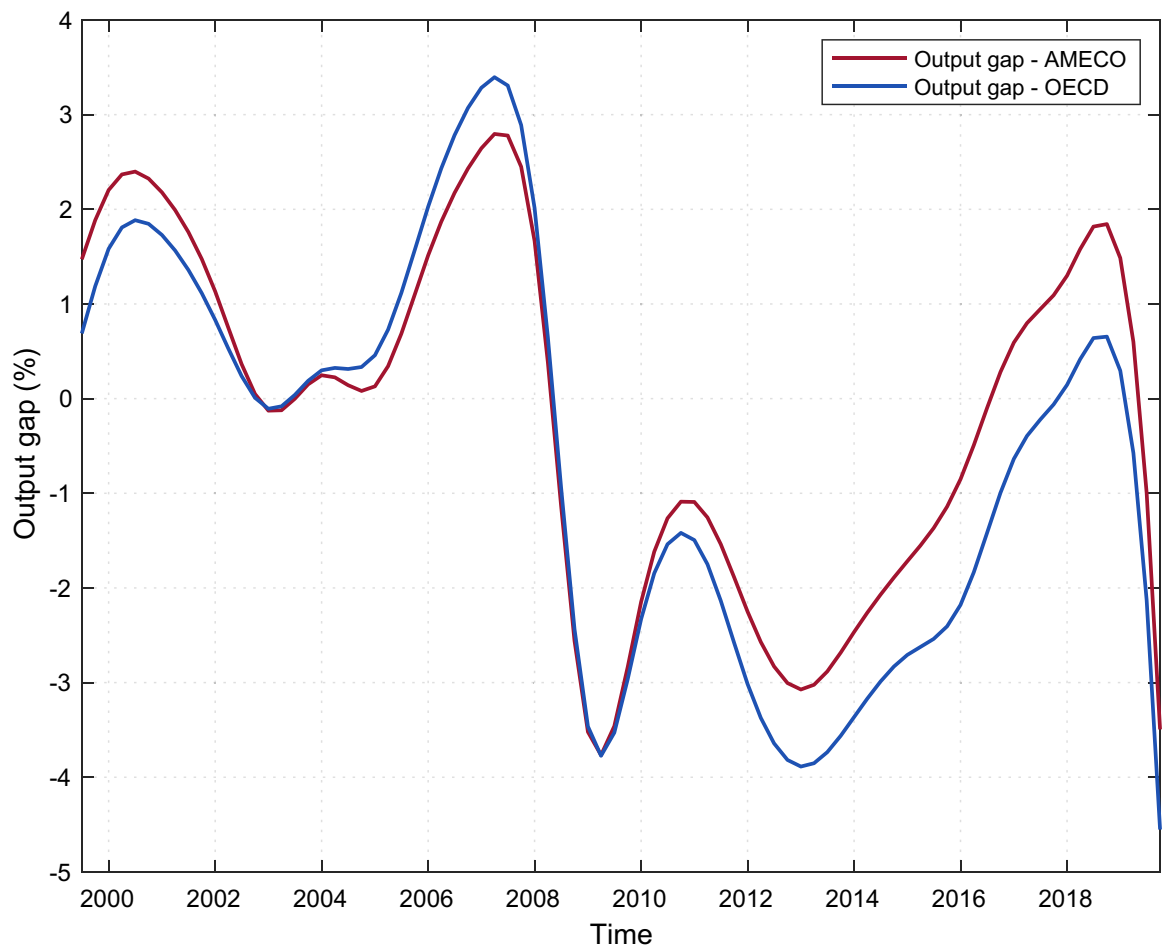

Fig. 1 Output Gap, AMECO and OECD, 1999-2019. Data Source: AMECO database and OECD Main Economic Indicators

the Eurosystem is "a year-on-year increase in the HICP for the EZ of below 2\%", 8 as stated by the ECB's Governing Council in 1998. Quarterly output gaps are obtained by implementing a cubic spline interpolation on AMECO and OECD annual data. ${ }^{9}$ For comparison, the two output gap time series are displayed in Fig. 1.

The expected inflation rate and expected GDP growth rate are reported as average point forecasts on a 12 months target period (1 year ahead). For our estimations we have also made use of forecasts on 24 months and 5 years target period. They are provided by the ECB Survey of Professional Forecasters (SPF). The expected inflation gap is computed as the difference of expected inflation with the target; the expected output gap is calculated as the difference between expected and potential

\footnotetext{
${ }^{8}$ Since the consensus on this quantitative target in the literature is not unique, but varies between $1.7 \%$ and $1.9 \%$, for robustness check we used both these values to calculate the inflation gap, using the latter as the reference value. The estimation results are exactly the same. The only affected term is the intercept, with OLS regression, for example, increasing from -0.136 (in the first case), to 0.064 (in the second one), not statistically significant in both cases).

${ }^{9}$ Again for robustness test, we ran our estimations using two sources for output gap data: AMECO and OECD, both providing only annual data. We use the first as the main source of our analysis, and the second to establish the robustness of our findings. Results from the latter are displayed in the "Appendix".
} 
Table 2 Summary statistics table, real and expected inflation gap

Table 3 Summary statistics table, real and expected output gap

\begin{tabular}{lclc}
\hline Percentiles & \multicolumn{2}{l}{ Value } & \\
\hline Inflation gap & & & \\
$10 \%^{\mathrm{a}}$ & -1.5 & Obs. $^{\mathrm{b}}$ & 82 \\
$50 \%$ & 0 & Mean & -0.19146 \\
$90 \%$ & 0.73 & Variance & 0.86523 \\
Expected inflation gap & & \\
$10 \%$ & -0.736 & Obs. & 82 \\
$50 \%$ & -0.25 & Mean & -0.28317 \\
$90 \%$ & 0.073 & Variance & 0.093654 \\
\hline
\end{tabular}

Data Source Inflation gap data are from Eurostat database; Expected inflation gap is calculated on expected inflation from ECB Survey of Professional Forecasters.

${ }^{\text {a }}$ This is the 10th percentile. Percentiles are calculated by ordering the values of a variable from lowest to highest, and then finding the value that corresponds to the percent, in this case, $10 \%$. Hence, $10 \%$ of the values of the variable are equal to or less than -1.5

${ }^{b}$ Number of valid observations (i.e., not missing) for the variable

\begin{tabular}{lclc}
\hline Percentiles & \multicolumn{2}{l}{ Value } & \\
\hline Output gap & & & \\
$10 \%$ & -2.8493 & Obs. & 82 \\
$50 \%$ & 0.13572 & Mean & -0.16637 \\
$90 \%$ & 2.2399 & Variance & 3.5212 \\
Expected output gap & & \\
$10 \%$ & -2.8396 & Obs. & 82 \\
$50 \%$ & 0.080187 & Mean & -0.23529 \\
$90 \%$ & 1.9554 & Variance & 3.0825 \\
\hline
\end{tabular}

Data Source Output gap data are from AMECO (database); Expected Output gap is calculated on expected GDP from ECB Survey of Professional Forecasters

GDP, as a percentage of potential GDP (PGDP). ${ }^{10}$ A more detailed description of the data is reported in Table 2 (summary statistics of the actual and expected inflation gap) and Table 3 (summary statistics of the actual and expected output gap).

First, two interesting elements emerge from Table 2: the difference in the variables ranges between the 10th and 90th percentile ( 2.23 for actual inflation, 0.81 for the expected one) and in the variance (the variance of the actual gap is 9 times larger

\footnotetext{
${ }^{10}$ In order to obtain quarterly PGDP data, only available on annual basis, we employed the equation used to calculate the output gap and extracted the value of PGDP from it (having already the value of GDP and output gap). GDP data are defined as chain linked volumes at market prices (reference year 2015), in million of euro. Output gap data (both AMECO and OECD) are at constant prices (2015 reference levels). Hence PGDP is also expressed in chain linked volumes at constant market prices (2015).
} 


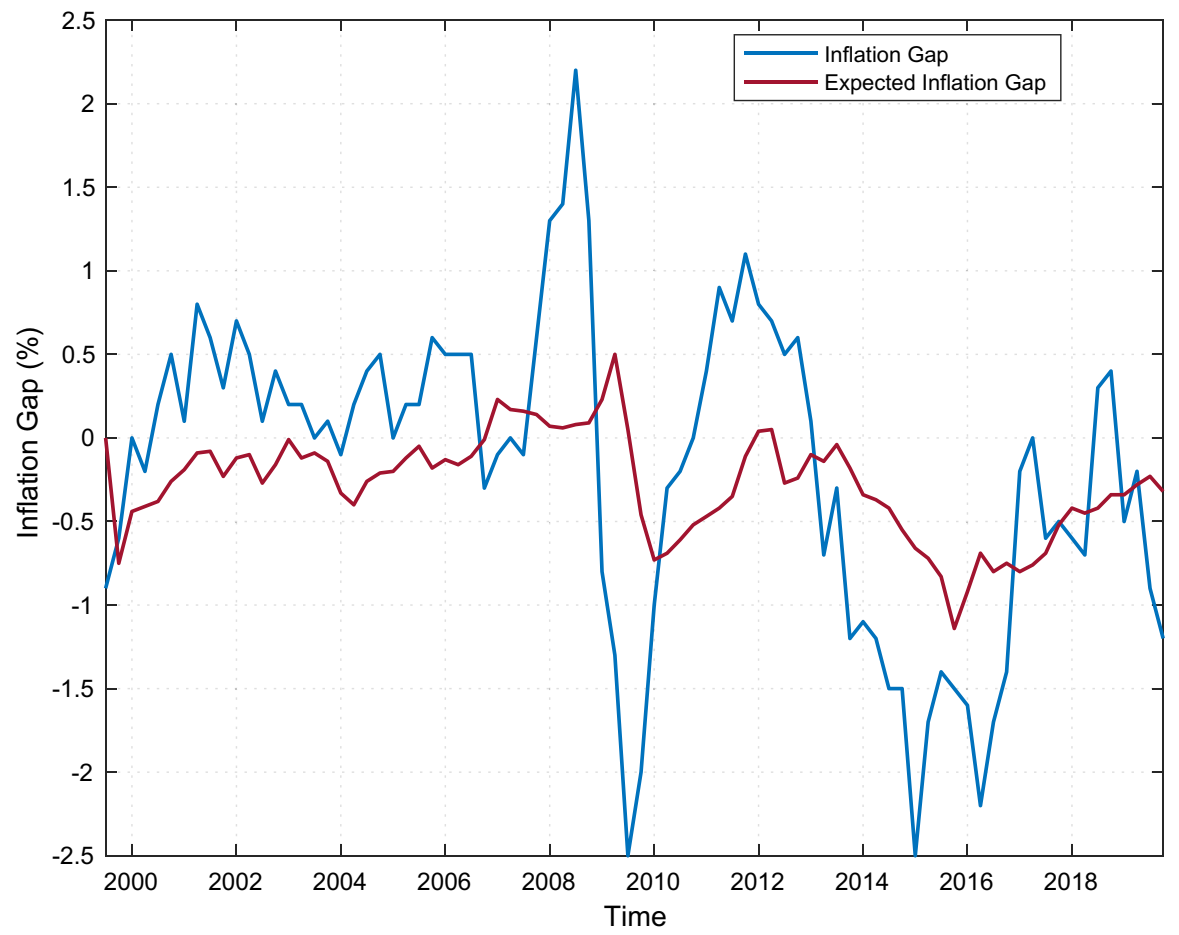

Fig. 2 Inflation Gap and Expected Inflation Gap, 1999-2019. Data Source Inflation gap data are from Eurostat database; Expected inflation gap is calculated on expected inflation from ECB Survey of Professional Forecasters

than for the expected gap). Both hint at the nature of agents' expectations, which are less volatile than observed inflation and fluctuate closer to the equilibrium level. In addition, expected values are on average lower than actual ones $(-0.28$ against -0.19 ), which reveals a potential pessimistic or prudential attitude of agents when building their forecasts on the inflation rate. This hypothesis is further confirmed by the fact that the median of expected values is negative $(-0.25)$, while the median of actual values is zero.

On the contrary, data on output gaps (Table 3) show a similar pattern between real and expected values. This is shown again by the variables percentile range (5.09 and 4.79) and variance (3.528 and 3.08), which do not differ significantly. Also in this case, output forecasts are on average lower than observed GDP $(-0.23$ against -0.17 ) but the median of expected gap is much lower (0.08 against 0.14$)$. This could entail a pessimistic behavior of agents when making output forecasts, resulting in an overestimation of gaps, even though it is rather a weak evidence. Indeed, as already explained in the previous section, the overestimation of GDP gaps (in absolute values) should then be reflected in the inflation gap by amplifying it, as described by Eq. 7. 


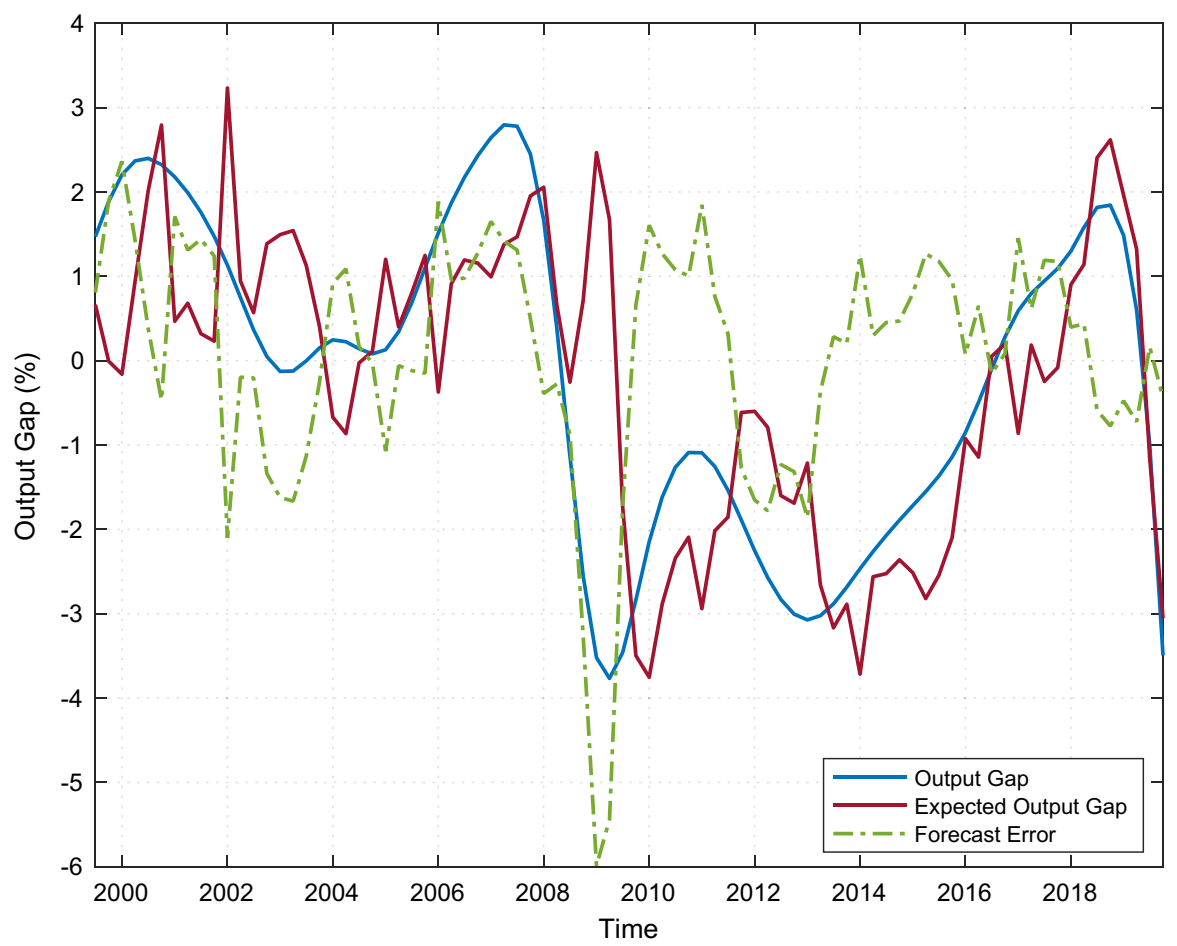

Fig. 3 Output Gap, Expected Output Gap and Forecast Error, 1999-2019. Data Source: Output gap data are from AMECO (database); Expected Output gap is calculated on expected GDP data from ECB Survey of Professional Forecasters

To better understand the dynamics at work, let us now turn to the pattern the data exhibit over time. As shown in Fig. 2, expectations of the inflation gap have been well anchored (close to zero) from the beginning of the 2000's to 2008 (in correspondence with the outbreak of the financial crisis). From that point on, expectations have fallen about 1 point below the target, showing a higher sensitivity with respect to the trend of observed inflation. This would confirm the hypothesis of de-anchoring of inflation expectations endorsed by a growing number of scholars in last years.

Similarly, the expected output gap (Fig. 3) has remained quite stable around the GDP gap until 2009, when agents have dramatically failed to predict the abrupt drop in the output level of the EZ, as highlighted by the fall in the forecast error value (-6.5\%). After 2010, instead, the gap between real and expected output has decreased again (in absolute value).

Some preliminary considerations can already be made here. First, a general positive co-movement of output and inflation gap, although with some lag, appears between the two series. Second, it is not negligible the role of negative forecast errors in counterbalancing the effect of output gap on inflation. This is particularly evident in the period 2011-2013 (when the "missing deflation" puzzle arises) and 


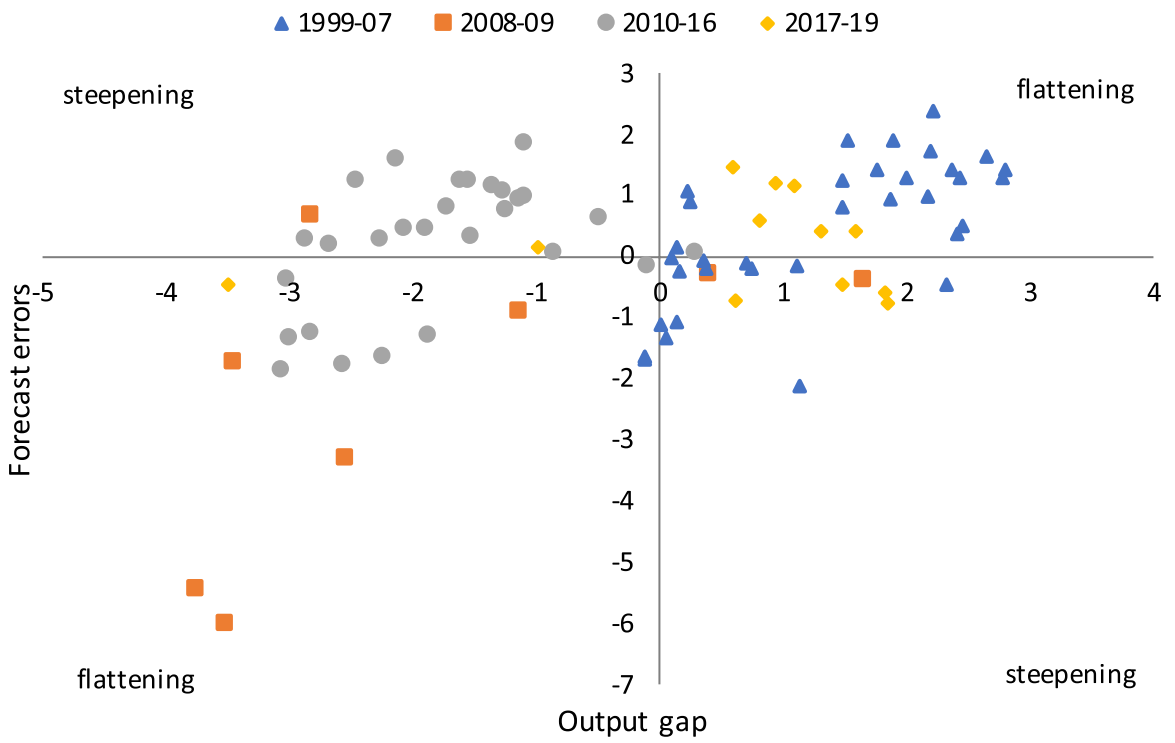

Fig. 4 Forecast errors vis-à-vis output gaps, 1999-2019

2017-2019 (when we observe a "missing inflation" problem). These observations seem to be quite in line with the predictions of our theoretical model.

So key to our model of the PC is the compound effect of both output gaps and agents' forecast errors. The effects of the four combinations of these variables on the PC were summarized in Table 1 . Those combinations can easily be mapped onto the data by means of the dispersion graph presented in Fig. 4 which plots forecast errors against output gaps. The labels of the four quadrants of the graph reproduce the combinations in Table 1.

The output gaps are divided in four phases: pre-crisis (1999-2007), recession (2008-2009), depression (2010-2016), recovery (2017-2019). In the pre-crisis and recovery phases both output gaps and forecast errors are mostly positive or close to zero (output gaps are underestimated), hence the predicted result is a flatter PC. In the recession phase, both output gaps and forecast errors are mostly negative (again, output gaps are underestimated), keeping the PC flat. In the depression phase, instead, systematically negative output gaps are mostly associated with positive forecast errors, i.e. they are overestimated by agents, creating a steeper PC. These predictions of changing slopes of the PC fit remarkably well the puzzles in the literature, discussed in the previous sections, about missing inflation in the pre-crisis and recovery phases, missing deflation in the aftermath of the recession, and excess deflation in the depression phase, with a clear impact of de-anchored expectations.

Having identified the role of output gap and forecast errors in conditioning the slope of the PC, a few additional considerations may be in order. Whatever method agents use to form their expectations, forecast errors are inevitable, even in the REH limit case of agents holding the "true" statistical expectation of the (stochastic) variable. On the other hand, forecast errors are also a symptom of uncertainty, indeed 
they are the correct measure of uncertainty according to Jurado et al. (2015). Hence it is not by chance that in the EZ forecast errors have become critical as amplifiers of the depression phase in conjunction with the de-anchoring of expectations, that is in a spell of increasing uncertainty. The same phenomenon can be expected to materialize if greater uncertainty and de-anchoring of expectations take place in the run-up of inflation, steepening the PC and fueling the inflationary process. If these considerations are correct, we may also conclude that time-varying uncertainty, reflected into larger "unforecastability" à la Jurado et al. (2015), broadens the set of factors that impinge on the conundrum of the slope of the PC.

\subsection{Econometric analysis and results}

In accordance with recent literature on the empirical analysis of the expectationaugmented Phillips Curve (e.g. Paloviita 2008; Busetti et al. 2017), and assuming our theoretical Eq. (7) to take the form of a linear model, a standard estimation procedure for multiple linear regressions, ordinary least squares (OLS), is employed for the estimation.

First issue to consider in time series analysis is the degree of correlation among residuals. Both auto and partial-autocorrelation plots reveal the presence of significant autocorrelation of first order. ${ }^{11}$ Moreover, tests for multicollinearity (Belsey's diagnostics) and conditional heteroscedasticity (Engle's ARCH Test ) are run on the model. For the first test the null hypothesis is not rejected; for the second it is rejected (see "Appendix"). Heteroscedasticity and autocorrelation robust standard errors (HAC) have then been employed in the OLS regression. Another possible issue which is more difficult to detect, is the endogeneity problem. In order to prevent possible sources of endogeneity (unobserved heterogeneity, simultaneous causation, measurement error), which would cause OLS to be biased, we have employed additionally a GMM estimation method, ${ }^{12}$ which provides instead consistent results in the presence of endogeneity.

We report the results from OLS and GMM estimation of model (10) in Table 4. For robustness check, we have estimated our model using two different sources for output gap data: the AMECO and the OECD database. Results from the latter are reported in the "Appendix" (see Table 6). Estimated coefficients (all statistically significant at conventional levels) are quite reasonable and coherent with our theoretical model. In particular, an increase of $1 \%$ in the output gap, leads to an increase of the inflation gap between $0.24 \%$ (in OLS) and $0.28 \%$ (in GMM); on the contrary,

\footnotetext{
11 Note that with time series data, it is highly likely that the value of a variable observed at time $t$ is persistent or simply similar to its lagged values; therefore when fitting a regression model to time series it is common to find autocorrelation in the residuals. In this case an OLS estimation could still be unbiased, but it would need a correction of the standard errors.

12 The Generalized Method of Moments is a general method for estimating parameters. It is widely applied when the full shape of the data distribution function is not known. It employs moment conditions allowing IV to break down autocorrelation or endogeneity problems in the estimation. In estimating our model, the instruments used are the 1 and 2 quarters lagged value of output gap and the 1 and 2 quarters lagged value of forecast error.
} 
Table 4 Phillips Curve linear regression table

\begin{tabular}{llll}
\hline & OLS & GMM & GMM \\
& $(1)$ & $(2)$ & $(3)$ \\
& QS & QS & QS \\
\hline out $_{t}$ & 0.244 & 0.265 & 0.276 \\
& $(0.0526)$ & $(0.0017)$ & $(0.0069)$ \\
err $_{t, t-4}$ & -0.218 & -0.113 & -0.248 \\
& $(0.0859)$ & $(0.0337)$ & $(0.0078)$ \\
cons & -0.136 & -0.126 & -0.082 \\
& $(0.0969)$ & $(0.1045)$ & $(0.0401)$ \\
Obs & 82 & 81 & 80 \\
$R^{2}$ & 0.212 & & \\
\hline
\end{tabular}

The table reports estimated Eq. (10). Output gap and forecast error use data from AMECO database. Column (1) contains OLS estimated coefficients, while columns (2) and (3) contain GMM with IV estimated coefficients. Instruments: lagged output gap out $t_{t-1}$ and lagged forecast-error err $_{t-1, t-5}$ in column (2); additional lagged output gap out $t_{t-2}$ and lagged forecast-error $\mathrm{err}_{t-2, t-6}$ in column (3). The sample period is 1999Q3-2019Q4, 82 observations. Dependent variable is the quarterly inflation gap (year on year). QS indicates Quadratic Spectral (HAC) standard errors. Andrews GMM weight matrix. $\mathrm{SE}$ are displayed in parentheses

a $1 \%$ increase in the forecast error implies a drop of the inflation level $0.22 \%$ with OLS estimation, while the reduction decreases to $0.11 \%$ in GMM when employing the 1 lag IV (it increases instead to 0.25 with a 2 lags IV). Moreover, when adding additional lags as IV, hence employing more than one instrument for each explanatory variable, the magnitude of both the output gap and the forecast-error coefficients (column 3 ) further increases. ${ }^{13}$ Thus the sensitivity of inflation to the output gap would be far from being negligible. In addition, the "shifting effect" of forecast error (which increases or reduces the output gap impact depending on whether the sign of the error is negative or positive, respectively) is also considerable.

What happens instead when employing longer-term forecasts instead of usual 1-year predictions? In Fig. 5 forecast errors with different prediction horizons are illustrated. As it can be seen, short and long term forecasts do not differ significantly over time, in particular expectations with 2 and 5 years horizons (the two lines overlap for almost the entire time interval). This should not sound strange, considering that agents make predictions on different horizons in the same moment, so that the information available they rely on are identical. ${ }^{14}$

\footnotetext{
${ }^{13}$ Because of having more moment conditions than parameters to be estimated, we have run the Hansen's J statistic, used for testing over-identifying restrictions. The null hypothesis has not been rejected, hence we consider our model to be correctly specified.

${ }^{14}$ In this respect, the ECB Statistical Data Warehouse has a specific section named "Assumptions", in which data underlying the forecasts provided by the professional forecasters are reported.
} 


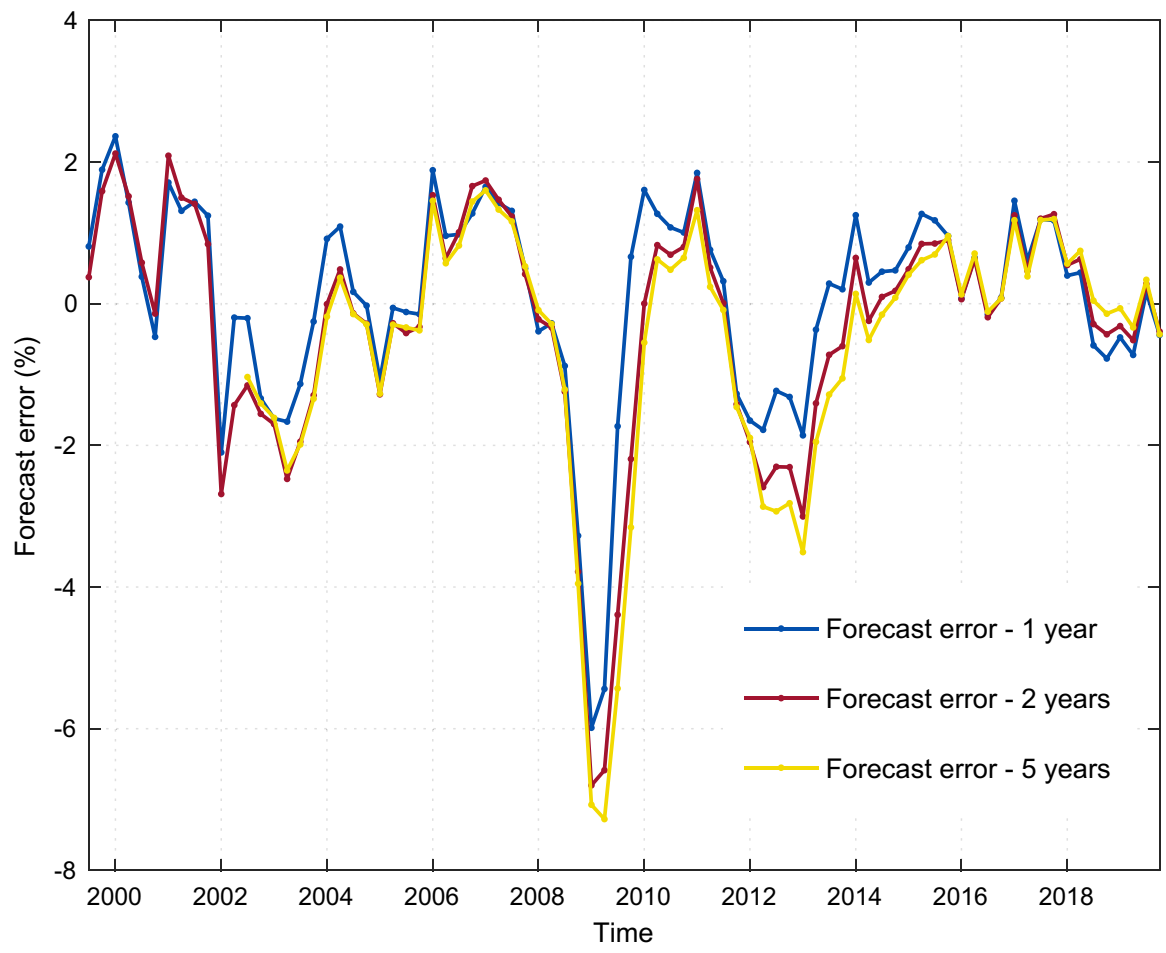

Fig. 5 Forecast Error, 1-year, 2-years and 5-years target period, 1999-2019. Data Source: Output gap data are from AMECO database; Expected Output gap is derived from expected GDP growth from ECB Survey of Professional Forecasters

Interestingly, long and medium term expectations depart from short ones in two precise points: once around 2009-2010, another between 2012 and 2014 (which represent even the lowest points in forecast errors series). The most credible hypothesis is that short-term expectations, although far from the real value of the output gap, as shown by the negative value of the forecast error, have benefited from the possibility of gleaning from recent information. On the contrary, longerterm expectations have suffered from agents' inability to make correct long-term forecasts. The fact that 2 and 5-years error terms are larger (in absolute value) might be due to greater optimism that agents have with respect to output growth in the distant future.

In order to test the explanatory power of longer-term expectations, we have employed the same OLS and GMM regression as before, substituting the 1-year forecast error variable respectively with 2 and 5-years error term. Estimation results are reported in Table 5. When comparing these outcomes to those reported in Table 4, we immediately notice two facts: the first is that the output gap coefficients do not diverge significantly, whatever kind of expectation we employ in the estimation (they are slightly higher with medium and long-term expectations with respect to estimation with short-term ones); the second is that, on the contrary, 
Table 5 Phillips Curve Linear Regression Table, medium and long-term forecasts

\begin{tabular}{lllll}
\hline & OLS & GMM & OLS & GMM \\
& $(1)$ & $(2)$ & $(3)$ & $(4)$ \\
& QS & QS & QS & QS \\
\hline out $_{t}$ & 0.262 & 0.279 & 0.268 & 0.284 \\
& $(0.0552)$ & $(0.0189)$ & $(0.0635)$ & $(0.0185)$ \\
err $_{t, t-8}$ & -0.177 & -0.094 & & \\
& $(0.0824)$ & $(0.0524)$ & & \\
err $_{t, t-20}$ & & & -0.159 & -0.076 \\
& & & $(0.0983)$ & $(0.0676)$ \\
cons & -0.200 & -0.159 & -0.210 & -0.154 \\
& $(0.0966)$ & $(0.1119)$ & $(0.1067)$ & $(0.1514)$ \\
Obs & 82 & 81 & 70 & 69 \\
$R^{2}$ & 0.213 & & 0.203 & \\
\hline
\end{tabular}

The table reports estimated Eq. (10). Columns (1) and (3) contain OLS estimated coefficients, while columns (2) and (4) contain GMM with IV estimated coefficients. Instruments: lagged output gap out $_{t-1}$ and lagged forecast error $e r r_{t-1, t-9}$ and $\operatorname{err}_{t-1, t-21}$. The sample period is 1999Q3 - 2019Q4, 82 observations. Dependent variable is the quarterly inflation gap (year on year). QS indicates Quadratic Spectral (HAC consistence) standard errors. Andrews GMM weight matrix. SE are displayed in parentheses

the coefficient associated with the forecast error decreases significantly (in absolute term) as the target period increases. Indeed the lowest value of $\gamma_{2}$ is reached for GMM estimation with err $_{t, t-5}{ }^{15}$ (column 4 of Table 5). This result is quite reasonable. As already stated above, short-term expectation benefit from the quality (and quantity) of information available at the time professional forecasters provide their predictions in the surveys. This suggests that the more distant in time forecasts are built, the lower is their explanatory power over inflation gap (and so the higher is the output gap's one).

It might be wise however to consider alternative approaches to our modeling, in order to enrich the analysis. It is indeed true that another crucial question may arise when employing time-series in a regression, that is the stability of parameters over time. In the presence of significant structural breaks in the $\hat{\gamma}_{s}$, the estimated model might be not completely reliable. A clear representation of this issue comes from the graph in Fig. 6. Here it is represented the evolution of the output gap and forecast error estimated coefficients of Eq. (10), obtained by employing a recursive OLS regression with Newey-West robust standard errors. ${ }^{16}$ As illustrated, the two

\footnotetext{
${ }^{15}$ Nevertheless, err $_{t, t-5}$ is not significant at the $90 \%$ neither with OLS, nor with GMM.

16 The recursive approach makes use of an increasing window to re-estimate the model; recursive regressions using nested windows are often employed to look for instability in explanatory models.
} 


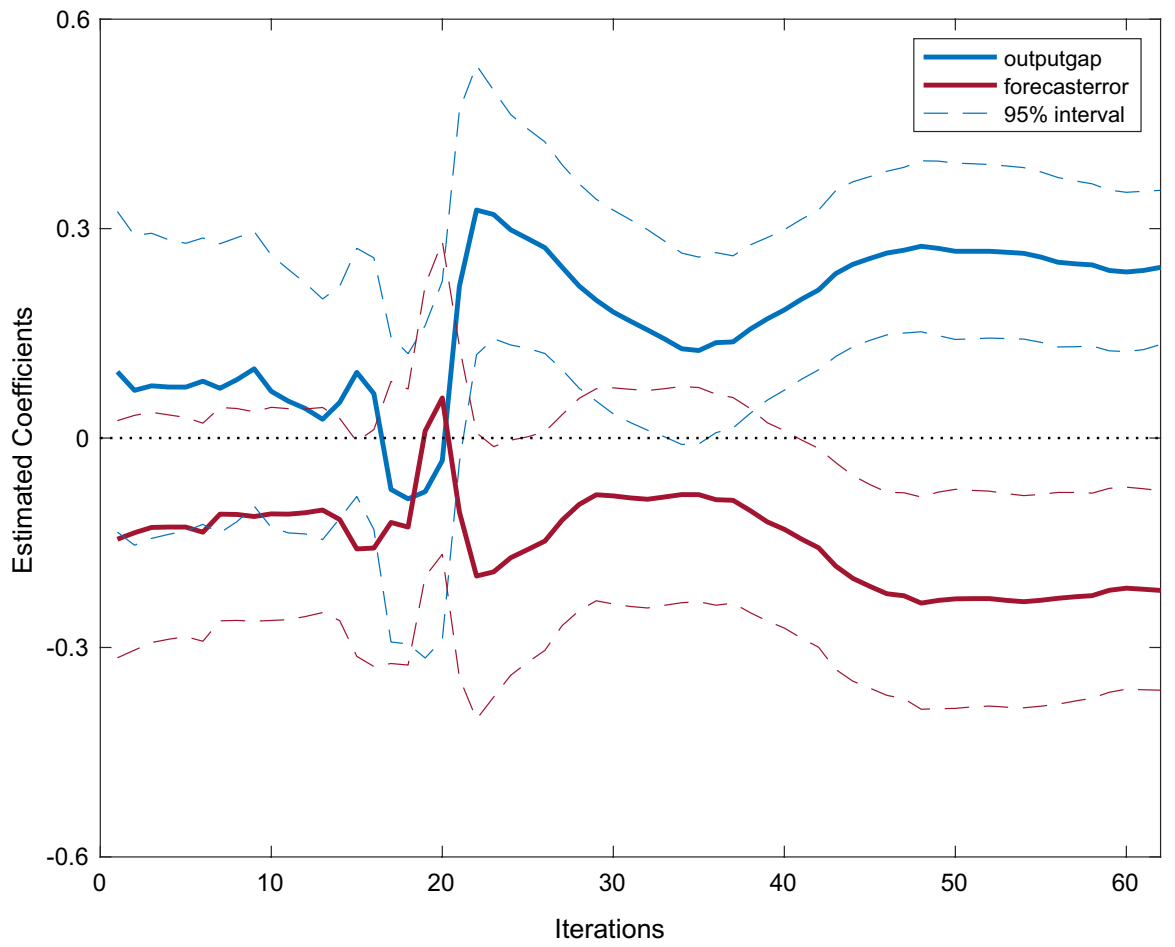

Fig. 6 Output Gap and Forecast error Coefficients, Recursive linear regression of model (10) Notes: The graph is obtained by employing a recursive (nested-window) regression on Eq. (10). Number of iterations is reported on th $\mathrm{x}$-axis

parameters are quite unstable, as they rapidly change direction as new data are added in the process. ${ }^{17}$ In particular, 3 main structural breaks appear around iteration 30 , 40 and 50. Further evidence of coefficient instability is provided by the structural change tests "Cumulative-sum-test" (Cusum) and "Chow-test". As a robustness check, we have tested an additional linear model in which six new variables were included: these were the result of the interaction between the two explanatory variables and three time-dummies, corresponding to the main structural breaks detected by the tests, respectively 2009-Q1, 2011-Q3 and 2013-Q4. ${ }^{18}$ The employment of

\footnotetext{
${ }_{17}$ Consider that recursive nested-window estimates typically show a high volatility during the initial "burn-in" period, because of the low number of observation in the sub-sample, which is slightly larger than the number of parameters in the model; hence the first 20 iterations are dropped from the figure below. After this "trial" period, any further volatility should be considered as evidence of coefficient instability.

${ }^{18}$ If we look at the circumstances occurring during the Great Recession in Europe around these specific quarters, we can easily understand why they can represent a "break" in the usual relations between the main macroeconomic variables. For example, at the end of 2008, the number of Countries entering the recession reaches its peak and the inflation level drops significantly. At the beginning of $2011 \mathrm{UK}$ and Portugal announce a significant worsening of the recession, while many other European countries see their public-debt-to-GDP ratios to increase, in contrast to the USA. In 2014, despite the ongoing recovery, the EZ sees a further decline in inflation. What all these events have in common is the complete unpredictability, which may have led to greater uncertainty and a further deterioration in the confidence of economic agents in the ability of national
} 
dummy variables in the regression, accounting for the structural breaks, allowed us to use a standard OLS for the estimation. It is important to note that, as revealed by the "Chow-test", other minor breaks are present in the time series in use, but accounting for all of them would have resulted in a confused and overloaded model. Nevertheless, even the employment of those six dummies led to contradictory and not always statistically significant results. We preferred then a more structured and robust approach.

In order to address this issue, we have introduced in our analysis an alternative model specification which takes into account the evolution over time of parameters. In analyzing time series data, the assumption that coefficients are fixed throughout the entire sample period under study is not always reasonable (Harvey and Phillips 1982; Tucci 1995). One way to deal with it is then to assume that coefficients are a function of some smoothing variable at time $t$. Such model is called time-varying coefficient linear model, which in our case is defined as follows:

$$
\inf _{t}=\alpha+\gamma_{1}\left(z_{t}\right) \text { out } t_{t}+\gamma_{2}\left(z_{t}\right) \operatorname{err}_{t, t-i}+u_{t} \quad \text { and } \quad t=1, \ldots, T
$$

where $z_{t}=\tau=t / T$ is the rescaled time allowing our $\gamma_{j}$ to vary over time. ${ }^{19}$ In so doing, the time-varying coefficients turn out to be unknown functions of time, as $\gamma_{j}\left(z_{t}\right)=f_{j}(\tau)$. Collecting the explanatory variables in the column vector $\mathbf{X}_{t}$, the dependent variable in $Y_{t}$, and the time-varying parameters in the vector $\boldsymbol{\gamma}\left(z_{t}\right)$, we can express the model as:

$$
Y_{t}=\mathbf{X}_{t}^{\prime} \gamma\left(z_{t}\right)+u_{t}
$$

Then the sample estimator is proportional to an OLS estimator, net of a weighting function $p_{b}$; the result is a series of weighted local regressions with a specific window size $b$ (bandwidth):

$$
\begin{gathered}
\hat{\gamma}\left(z_{t}\right)=\left(p_{b} \mathbf{X}^{\prime} \mathbf{X}\right)^{-1}\left(p_{b} \mathbf{X}^{\prime} \mathbf{Y}\right) \\
p_{b}=K\left(\frac{z_{t}-z}{b}\right)
\end{gathered}
$$

where $K$ is a kernel function, $b$ sets the dimension of the bandwidth. An extensive description of computational implementation of these kind of models is provided by Casas and Fernández-Casal (2019). Without prejudice to the importance of linear models, an estimation with time-varying regressors (tvReg) ${ }^{20}$ allows us to verify how the sensitivity of the inflation gap changes over time with respect to the output

Footnote 18 (continued)

and supranational institutions to cope adequately with the continuing crisis in the short term.

19 It exists an extensive literature on the implementation of time-varying coefficient models; see Beck (1983), Robinson (1989), Fan and Gijbels (1996), Fan and Zhang (2008).

${ }^{20}$ In particular, the one hereafter employed is a time-varying linear regression (tvLM). This methodology, as explained by the authors Casas and Fernández-Casal (2019), make use of a set of weighted local regressions with an optimally chosen window size. This size is given by a bandwidth, which can be automatically selected by cross-validation, or chosen manually. The lower the bandwidth, the more unders- 
(a) Time-varying Output Gap

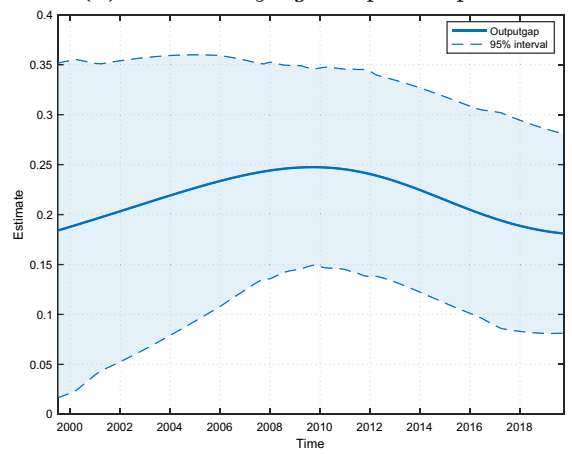

(b) Time-varying Forecast Error

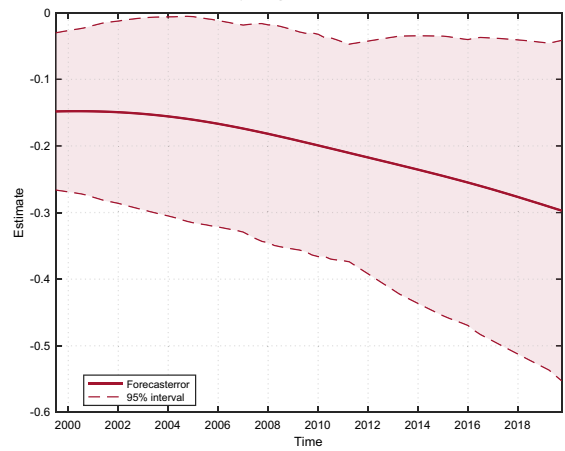

Fig. 7 Time-varying Coefficients regression. Notes: tvReg model uses the same formula as the linear function (10); "Gaussian" type kernel employed in the coefficient estimation. The selected bandwidth for time-varying regression is 0.3 . Output gap data are from AMECO database. Confidence interval at $90 \%$; 50 resamples used in the bootstrapping calculation

and agents' forecast error. Results from employing this procedure on our datasets are displayed in Fig. 7.

The panel on the left (a) shows the time-varying output gap coefficient; similarly, the one on the right (b) shows the time-varying forecast-error coefficient. The results suggest an important increase (in absolute value) in the forecast error coefficient, which doubles from 0.15 to 0.30 at the end of the sample. For what concerns the output gap coefficient, it reaches its peak in 2010 (0.25), after a slow increase from the initial value of 0.18 ; then it decreases back to the initial level. According to Eq. (7), the combined behavior of the two parameters could be determined by an increase in the sensitivity of inflation gap to output slack, in the form of a higher structural term coefficient $\beta_{2}$. There is however a clear and growing relative weight of output forecast errors in shaping the inflation gap.

In view of all this, the hypothesis relative to our endogenous-expectation PC can be confirmed and provide an explanation to the above-mentioned "inflation puzzles". In particular:

a the "missing deflation" puzzle in the aftermath of the recession (in particular between 2011 and 2013) coincides with a largely negative value of the forecasterror component, i.e. an initial underestimation of the worsening of output gaps (see Fig. 3); the negative value of the estimated $\hat{\gamma}_{2}$ from Eq. (10) would have then attenuated the impact of the output gap on prices, which explains why inflation has not fallen together with output;

Footnote 20 (continued)

moothed is the estimate. In our case, we opted for a relatively low bandwidth value to get smoothed and highly informative results. For the sake of completeness and robustness, we also fit this time-varying linear model using different bandwidth values. These estimations' results are reported in the "Appendix". 
b in the second half of the depression phase (between 2014 and 2016), we observe instead a rapid steepening of the curve: the positive forecast error indicates an overestimation of the negative output gaps (here between $-2 \%$ and $-1 \%$ ), strengthening their overall impact on the inflation gap (see Table 1);

c lastly, the "missing inflation" puzzle in the recovery phase (more evident between 2017 and 2019) is clearly explained by the positive value of the forecast error term (until 2018-Q2), which indicates a strong underestimation of the improvement of output gaps and hence a new flattening of the PC.

\section{Conclusions and future perspectives}

Some so-called "inflation puzzles" have led researchers to wonder whether the PC could still be a valid tool to estimate and foresee the relationship between inflation and the business cycle. In this paper we have shown that the basic expectationsaugmented PC can accommodate the relevant puzzles provided that its expectational component is no longer treated as an independent explanatory variable. Our idea, broadly consistent with the principles of rational expectations, and corroborated by independent evidence about how available inflation forecasts are elaborated, is that if agents rely on the PC to foresee inflation, then its expectational component should be endogenized accordingly. The result is a PC in which inflation depends no longer on its own expectations and the output gap, but on the output gap and its forecast errors. In this new formulation, output and inflation keep moving in the same direction, while forecast errors (calculated as the difference between forecasts and observed output) act in two opposite ways: they amplify the impact of output on inflation when agents overestimate the gap (the curve appears steeper), or, on the contrary, they reduce the impact when agents underestimate the gap (the curve appears flatter).

The hypotheses generated by the model are confirmed by the data collected on the EZ from 1999 to 2019 . The econometric analysis reveals not only that the structural component of the PC is not flatter than ever, but also that the model is able to explain the inflation puzzles and the various phases of apparent flattening and steepening of the PC during the life of the Euro. Of course, other explanatory variables might be added, but our purpose has been to check how well our reformulation of the basic PC may fare.

On the side of policy implications, the inflation puzzles have challenged the effectiveness of conventional and unconventional monetary policies in stimulating inflation and economic growth, particularly in the EZ in consequence of its institutional setup. Several scholars suggest a major change of direction in the policies undertaken by the ECB (e.g. Parliament European (2019) and Capolongo and Gros (2019)). One of these proposals would be that of a dual-mandate (similarly to the Federal Reserve) focusing not only on the price stability, but also on the progressive reduction of output and unemployment gap. Another one would focus on a possible range in which inflation could fluctuate, depending on current specific economic circumstances. A third view is that the low level of inflation persistently observed in the EZ is the result of a structurally flatter Phillips Curve, so that the ECB should 
reparametrize its target rather than struggling to push inflation up. The discrimination between the structural and transient expectational components of the PC proposed in this paper may provide valuable guidance in the search for better monetary policy making. For instance, in the case of the EZ, our finding that the missing inflation in the recovery phase (after 2016) is due to a large extent to the flattening effect of output expectations lagging behind actual developments suggests that it would be a mistake for the ECB to surrender to depressed expectations instead of being their driver.

Our empirical work is open to further developments in various directions. First, it would be important to extend the research to a country-level analysis, to investigate the impact of structural economic differences between countries in the EZ, or to test whether the model is also able to accurately predict the inflation behavior in the US economy. Furthermore, other variables could serve as a proxy for output forecasts, other than the Survey of Professional Forecasters, to better reproduce households' and firms' expectations along the lines of the empirical work by Coibion and Gorodnichenko (2015). In this regard, there exists the Consumer Surveys conducted by the Directorate General for Economic and Financial Affairs of the European Commission, though these are qualitative data that are difficult to integrate into an econometric model. ${ }^{21}$ Finally, beyond the effect of the output gap and forecast errors observed at a given point in time, our model may be extended towards mechanisms whereby agents learn from errors and seek to improve their output forecast capacity, along the lines indicated for instance by Jörgensen and Lansing (2019) in the case of inflation forecasts.

\section{Appendix}

\section{Survey of Professional Forecasters}

The ECB Survey of Professional Forecasters is conducted in the first month of every quarter since 1999, with different time horizons, from 3 months to 5 years. These surveys are submitted to a wide number of professionals (about 90) from all the EZ countries. Agents are asked to make forecasts about 3 main macroeconomic variable. In this work, we make use only of forecasts made on the following variables:

- Harmonized Index of Consumer Prices (HICP) inflation, published by Eurostat (Annual rates of growth);

- Real gross domestic product (GDP) according to the definition of the European System of National and Regional Accounts 1995 (ESA 95), published by Eurostat; annual rates of growth.

\footnotetext{
${ }^{21}$ In this respect, Lyziak and Paloviita (2016) quantify consumer expectations using a probability approach.
} 
(a) Autocorrelation

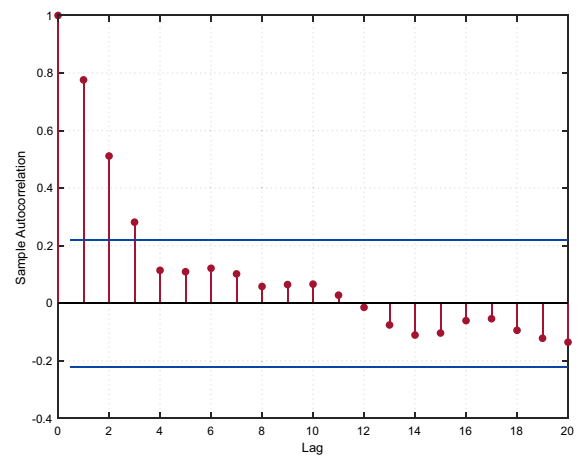

(b) Partial Autocorrelation

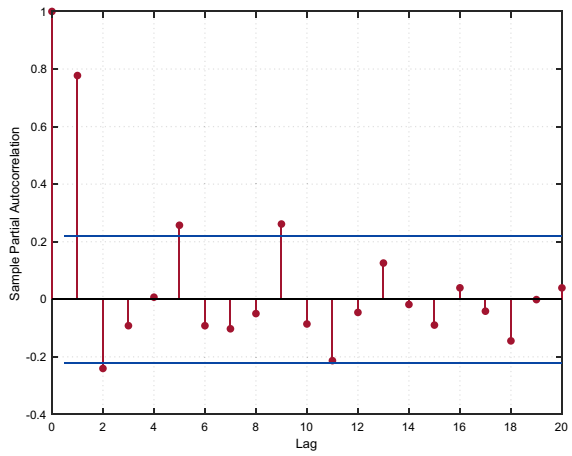

Fig. 8 Auto and Partial Autocorrelation test

For what concerns inflation surveys, the latest HICP inflation rate available to survey respondents at the time of expectations formation (survey deadline) refers to the last month of the previous quarter. Instead, for GDP surveys output latest projection at forecasters disposal refers to the projection published in the previous quarter. The surveys provide two classes of observation types: a probability distribution class, in which forecasters are asked to provide their personal probability distribution about the forecasted variable; a point forecast, in which forecasters have to indicate a single value for each variable at each time horizon. The latter is the one used in this work. A spreadsheet sample of the survey is available at the following website: https://www.ecb.europa.eu/stats/ecb_surveys/survey_ of_professional_forecasters/html/index.en.html\#background.

\section{Statistical tests}

Diagnostic checks for auto and partial autocorrelation are carried on the residuals of OLS regression. The produced plots show little sign of autocorrelation of order higher than 1; this is due to the fact that time series always have a certain level of persistence (remember for example the stickiness of prices theorized by Calvo (1983)). In plot 8, the estimated residual autocorrelation function is displayed on the left hand side and the estimated residual partial autocorrelation on the right one.

When removing from the model the influence of lags of order higher than 1 , the residuals-autocorrelation disappears.

Belsley's diagnostic checks for multicollinearity in linear regression. The default tolerance level for for this test is 30 . In this case the test result is:

- $\mathrm{B}=1.21$ 


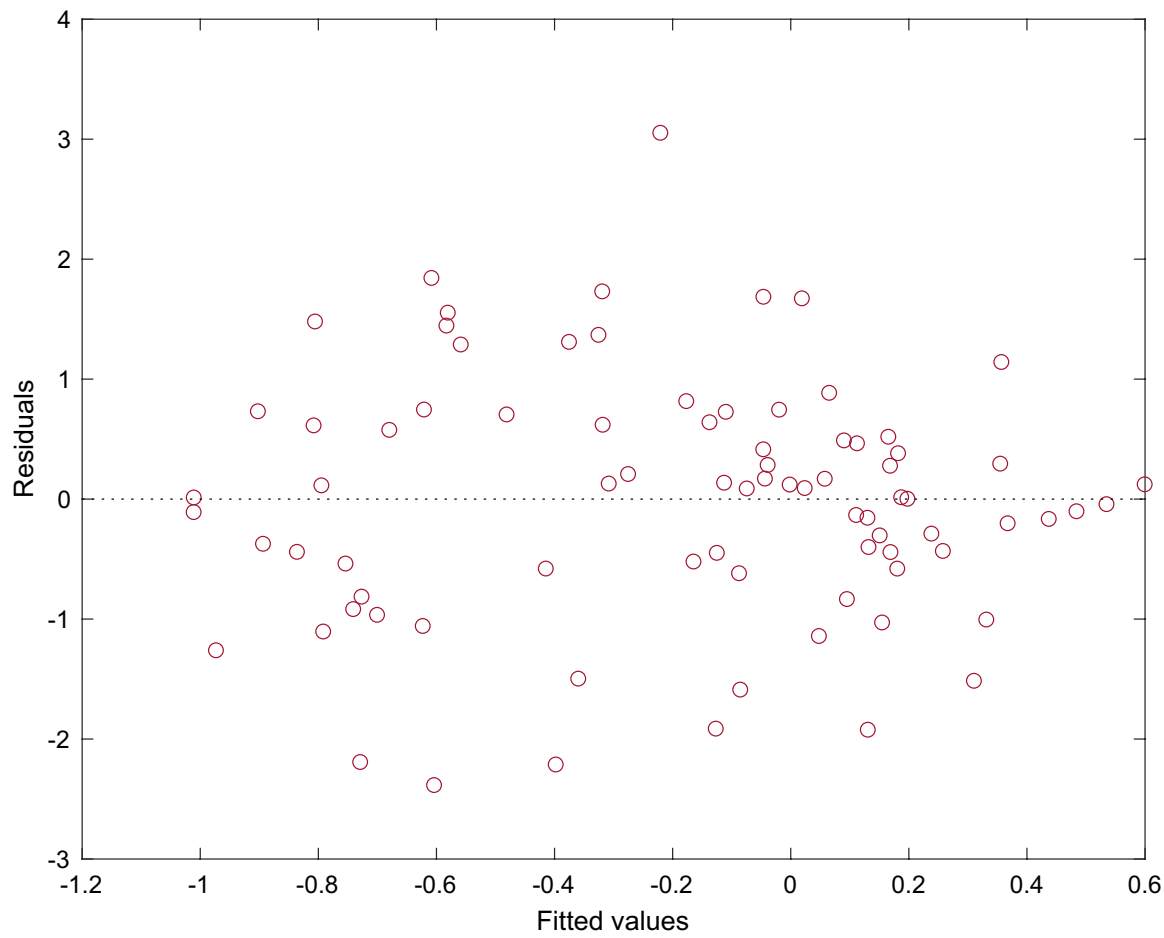

Fig. 9 Linear regression: residuals vs fitted values

hence, there is no evidence of multicollinearity.

After estimation, Engle's ARCH test is employed to check for errors conditional heteroscedasticity. The null hypothesis of constant errors' variance is rejected. The test result on our linear regression model is (Fig. 8):

- $\mathrm{ARCH}$ test $=25.833(\mathrm{p}$-value $=6.4901 \mathrm{e}-07)$

Robust standard errors are then employed in both OLS and GMM estimation procedures. Additional indication of heteroscedasticity is given in Fig. 9. The high volatility of residuals is self-explanatory.

Hansen's J statistic checks the validity of the over-identifying moment conditions in a GMM estimation with IV. In the cases reported in Table 4, the test result is:

- $\mathrm{J}$ test $=1.16766(\mathrm{p}$-value $=0.5578)$

hence, the null hypothesis is not rejected and the moment conditions employed are valid.

The Augmented Dickey-Fueller test checks the stationarity of variables. The null hypothesis is that the variable contains a unit root, while the alternative is that it follows a stationary process. ADF test up to 4 lags is conducted on the three main 
(a) Cumulative Sum Test, Coefficients' Stability in New Phillips Curve

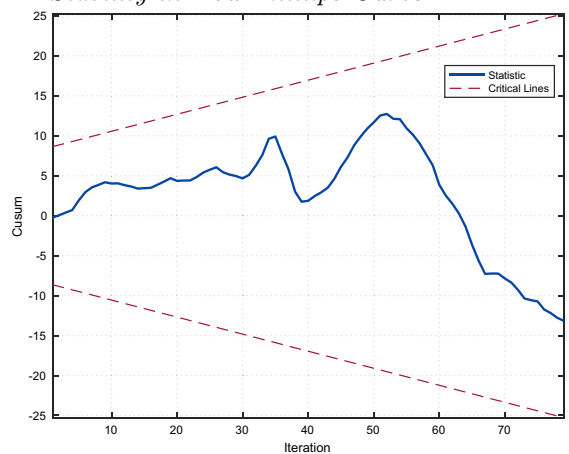

(b) Cumulative Sum Test-Squared, Coefficients' Volatility in New Phillips Curve

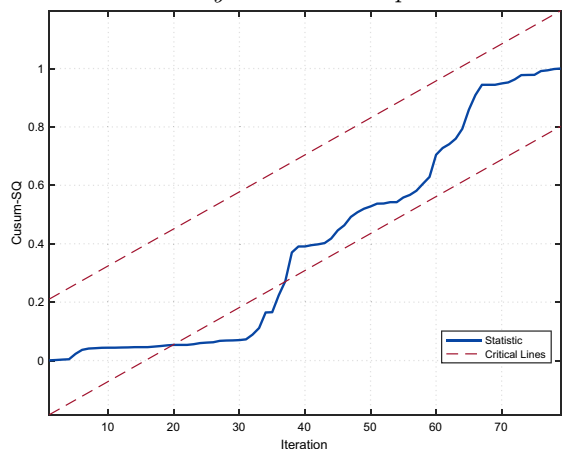

Fig. 10 Cumulative Sum Test. Notes: Cumulative sum test with 95\% confidence bands (dot lines). Total number of iterations produced by the process is 81 , equal to the total number of observations (83) minus 2

variables used; the null hypothesis is not rejected for inflation gap (except for the 4th lag) and forecast error, but it is rejected for output gap (except for the 1st lag). A further test on the stationarity of residuals after estimation, shows that they can be considered as stationary: therefore, the estimated relation is not a spurious regression.

The Cusumtest statistic is constructed from the cumulative sum of the OLS residuals to test coefficients' stability and for structural breaks due to changes in the model over time. The cumulative sum of squares test (CusumSq), instead, is used to detect possible structural breaks in volatility in simulated data. In our case, the null hypothesis of coefficients' stability is not rejected, since the blue statistic line never crosses the red confidence bands (Fig. 10a). On the contrary, the null hypothesis of stability in the volatility (Fig. 10b) is rejected, as the statistic line crosses the critical lines at least twice. Chow-test instead checks for possible structural breaks in the coefficients when the position of the breaks is known. Assuming they are unknown, we use a loop to test the presence of breaks on the entire sample. The outcome of the test reveals the existence of a multitude of breaks between iterations 30 and 70 .

\section{Robustness}

\section{Linear and Time-varying regression with OECD data}

We report here results of robustness checks to using OECD output gap data as an alternative source.

First the results from the OLS and GMM estimation of model (10) are displayed in Table 6. Estimated coefficients are in line with our previous results, thus validating our estimation approach. In details, an increase of $1 \%$ in the output gap positively affects the inflation level, which increases significantly (0.29\% (in OLS) and $0.33 \%$ (in GMM)); a $1 \%$ increase in the forecast error implies a contraction of the 
inflation gap of $0.14 \%$ with OLS estimation, up to $0.20 \%$ in GMM when employing a 2 lags IV.

In Table 7, we report estimation results of OLS and GMM with long-term forecast errors (2 and 5-years). The output gap coefficients increase whit GMM, and are slightly higher with respect to estimation with short-term expectations (as in previous estimation with the AMECO data, see Table 4). The same happens for the coefficients associated with the long-term forecast error, which increase significantly (in absolute term) when moving from OLS to GMM, and as the target period increases (from 2 to 5 years). However, in this case there is a discrepancy with the results reported in Sect. 3.2 of the paper. While here the error coefficients increase with the target and are always significant (at least at the 5\% level) the same does not happen when employing AMECO data. This conflicts with the idea that the more distant in time forecasts are built, the lower is the impact of forecast errors on inflation gap. This opposite behavior is of course dependent on the nature of the GDP data and on the (possibly) different methods that different institutions (the European Commission on one hand, the OECD on the other) employ to estimate the potential output. Nevertheless, in both cases the prediction of our theoretical model are verified.

Table 6 Phillips Curve linear regression table, OECD data

\begin{tabular}{llll}
\hline & OLS & GMM & GMM \\
& $(1)$ & $(2)$ & $(3)$ \\
& QS & QS & QS \\
\hline out $_{t}$ & 0.285 & 0.332 & 0.329 \\
& $(0.0516)$ & $(0.0778)$ & $(0.0042)$ \\
err $_{t, t-4}$ & -0.142 & -0.182 & -0.199 \\
& $(0.0453)$ & $(0.0064)$ & $(0.0069)$ \\
cons & -0.494 & -0.592 & -0.689 \\
& $(0.1307)$ & $(0.0995)$ & $(0.0324)$ \\
Obs & 82 & 81 & 80 \\
$R^{2}$ & 0.312 & & \\
\hline
\end{tabular}

The table reports estimated Eq. (10). Output gap and forecast error use data from OECD database. Column (1) contains OLS estimated coefficients, while columns (2) and (3) contain GMM with IV estimated coefficients. Instruments: lagged output gap out $t_{t-1}$ and lagged forecast-error $\operatorname{err}_{t-1, t-5}$ in column (2); additional lagged output gap out $_{t-2}$ and lagged forecast-error err $_{t-2, t-6}$ in column (3). The sample period is 1999Q3 - 2019Q4, 82 observations. Dependent variable is the quarterly inflation gap (year on year). QS indicates Quadratic Spectral (HAC) standard errors. Andrews GMM weight matrix. SE are displayed in parentheses 
Table 7 Phillips Curve Linear Regression Table, medium and long-term, OECD data forecasts

\begin{tabular}{lllll}
\hline & OLS & GMM & OLS & GMM \\
& $(1)$ & $(2)$ & $(3)$ & $(4)$ \\
& QS & QS & QS & QS \\
\hline out $_{t}$ & 0.301 & 0.358 & 0.295 & 0.362 \\
& $(0.0536)$ & $(0.0122)$ & $(0.0599)$ & $(0.0233)$ \\
err $_{t, t-8}$ & -0.138 & -0.178 & & \\
& $(0.0489)$ & $(0.0226)$ & & -0.193 \\
err $_{t, t-20}$ & & & -0.139 & $(0.0448)$ \\
& & & $(0.0703)$ & -0.748 \\
cons & -0.521 & -0.632 & -0.581 & $(0.2413)$ \\
& $(0.1534)$ & $(0.1537)$ & $(0.2462)$ & 69 \\
Obs & 82 & 81 & 70 & \\
$R^{2}$ & 0.213 & & 0.203 & \\
\hline
\end{tabular}

The table reports estimated Eq. (10). Columns (1) and (3) contain OLS estimated coefficients, while columns (2) and (4) contain GMM with IV estimated coefficients. Instruments: lagged output gap out $t_{t-1}$ and lagged forecast error $e r r_{t-1, t-9}$ and $e r r_{t-1, t-21}$. The sample period is 1999Q3-2019Q4, 82 observations. Dependent variable is the quarterly inflation gap (year on year). QS indicates Quadratic Spectral (HAC consistence) standard errors. Andrews GMM weight matrix. $\mathrm{SE}$ are displayed in parentheses (a) Time-varying Output Gap, OECD data

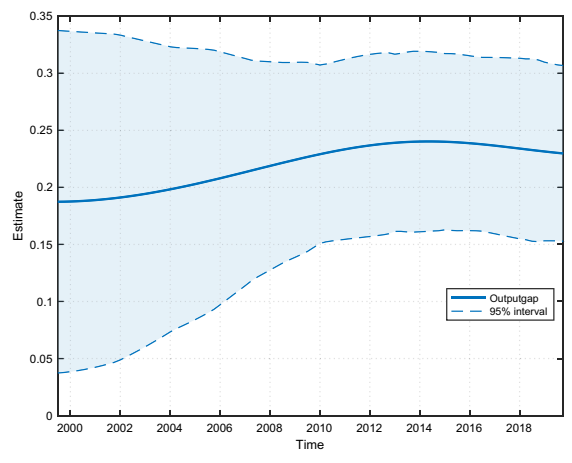

(b) Time-varying Forecast Error, OECD data

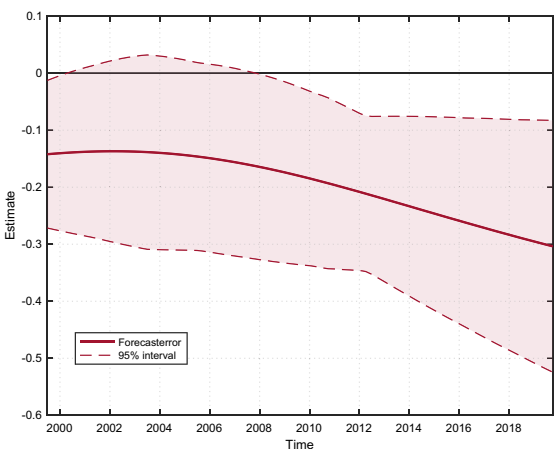

Fig. 11 Time-varying Coefficients regression. Notes: tvReg model uses the same formula as the linear function (10); "Gaussian" type kernel employed in the coefficient estimation. The selected bandwidth for time-varying regression is 0.3 . Output gap data are from OECD database. Confidence interval at $90 \% ; 50$ resamples used in the bootstrapping calculation 
(a) Time-varying Output Gap, AMECO data, bandwidth $=0.1$

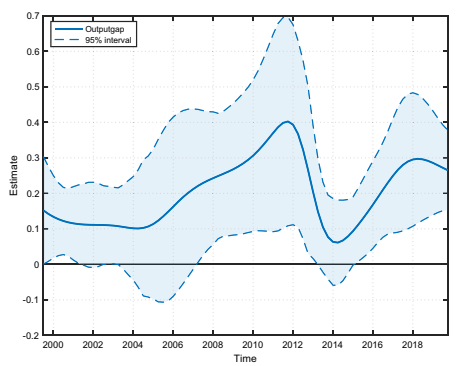

(c) bandwidth $=0.5$

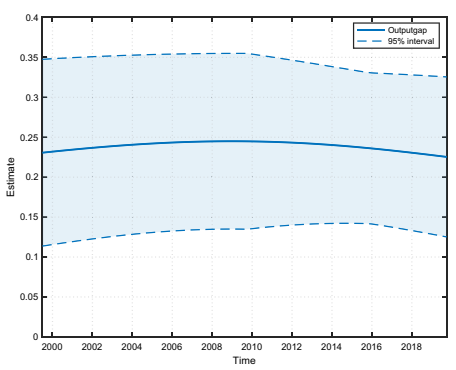

(e) Time-varying Output Gap, OECD data, bandwidth $=0.1$

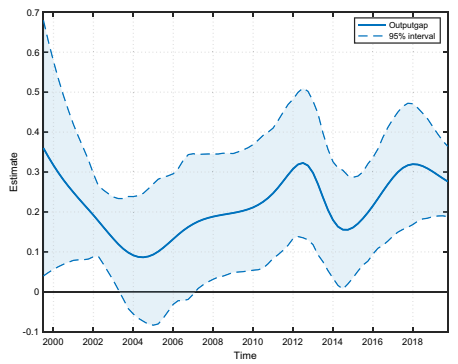

(g) bandwidth $=0.5$

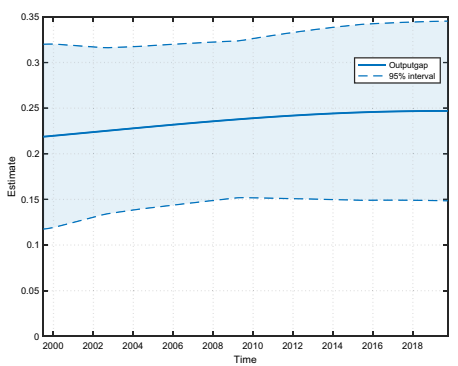

(b) Time-varying Forecast Error, AMECO data, bandwidth $=0.1$

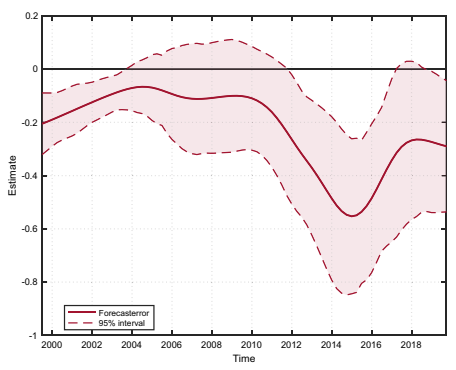

(d) bandwidth $=0.5$

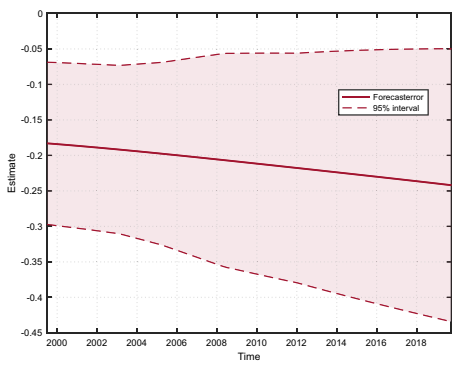

(f) Time-varying Forecast Error, OECD data, bandwidth $=0.1$

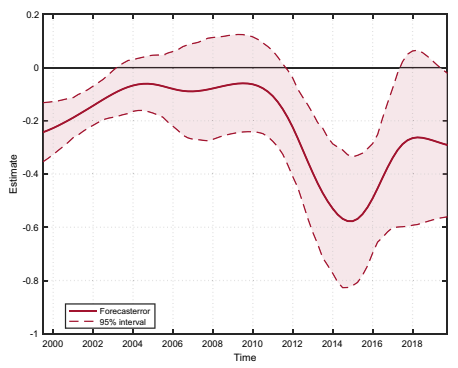

(h) bandwidth $=0.5$

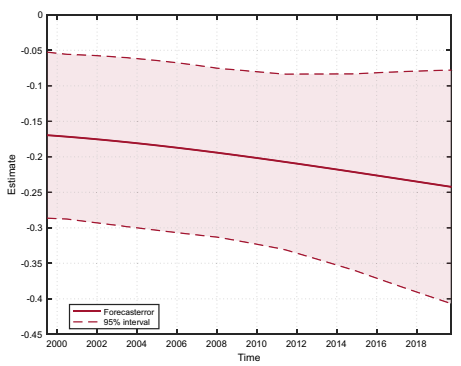


4 Fig. 12 Time-varying Coefficients regression. Notes: tvReg model uses the same formula as the linear function (10); "Gaussian" type kernel employed in the coefficient estimation. The selected bandwidth for time-varying regression is 0.1 in $\mathbf{a}, \mathbf{b}, \mathbf{e}$ and $\mathbf{f}, 0.5$ in the others. In $\mathbf{a}-\mathbf{d}$, output gap data are from AMECO database; in the other panels data are from OECD database. Confidence interval at $90 \% ; 50$ resamples used in the bootstrapping calculation

To assess the validity of our approach, we employ again a time-varying linear regression to estimate our model, using output gap time series from the OECD database. The results are displayed in Fig. 11. As in Fig. 7, the panel on the left (a) shows the time-varying output gap coefficient, while the one on the right (b) shows the time-varying forecast-error coefficient. Once again, the latter increases significantly (in absolute value). For what concerns the output gap coefficient, it constantly increases from 0.18 to 0.24 . Relying again on the relation described by Eq. (7), the combined behavior of the two parameters is a sign of a sensible increase in the reactiveness of inflation to output slack (the structural term coefficient $\beta_{2}$ increases).

\section{Time-varying regression with different bandwidth}

For the sake of completeness and robustness, we further report here (Fig. 12) the results from two time-varying coefficients estimations (tvLM) in which 2 different bandwidth values are employed; each of them has been calculated using both available datasets for output gap data (AMECO and OECD). In the first the selected bandwidth is equal to 0.1 , a much lower value with respect to that employed in the tvLM described in Sect. 3, so to obtain highly undersmoothed coefficients. Both estimated parameters are coherent with the prescriptions of our model, however they are both clearly more unstable than the corresponding estimated parameters described in previous section. In particular, both change abruptly direction twice, in correspondence of those that have been already defined as significant structural breaks in the time series, that is to say around 2011 and 2014. However, we do not consider this result to invalidate in any way the conclusions already drawn in the previous analysis. In the second estimation instead, the bandwidth value equals 0.5 , a higher value with respect to all the others so far employed. As expected, the result is a set of highly oversmoothed coefficients. Additionally, it is clear from these plots that the same line of reasoning applies for both datasets.

Supplementary Information The online version contains supplementary material available at https://doi. org/10.1007/s10663-021-09515-8.

Acknowledgements An earlier version of this paper was presented at the XX International Summer School "Macroeconomic Topics: Inefficiencies and Coordination Failures", University of Trento, Trento (Italy) 2019. We gratefully acknowledge valuable comments and suggestions from an anonymous referee of this Journal. We remain fully responsible for this paper.

Funding Open access funding provided by Università degli Studi di Trento within the CRUI-CARE Agreement. 
Open Access This article is licensed under a Creative Commons Attribution 4.0 International License, which permits use, sharing, adaptation, distribution and reproduction in any medium or format, as long as you give appropriate credit to the original author(s) and the source, provide a link to the Creative Commons licence, and indicate if changes were made. The images or other third party material in this article are included in the article's Creative Commons licence, unless indicated otherwise in a credit line to the material. If material is not included in the article's Creative Commons licence and your intended use is not permitted by statutory regulation or exceeds the permitted use, you will need to obtain permission directly from the copyright holder. To view a copy of this licence, visit http://creativecommons.org/licen ses/by/4.0/.

\section{References}

Bank of Ireland (2014) Examining the sensitivity of inflation to the output gap. Quarterly bulletin

Beck N (1983) Time-varying parameter regression models. Am J Polit Sci 27(3):557-600

Bernanke BS (2007) Inflation expectations and inflation forecasting. Speech at the monetary economics workshop of NBER Summer Institute. Cambridge, MA

Blanchard OJ, Cerrutti E, Summers L (2015) inflation and activity. Two explorations and their monetary policy implications. IMF working paper 15.230

Bobeica E, Sokol A (2019) Drivers of underlying inflation in the euro area over time: a Phillips curve perspective. ECB economic bulletin, Issue 4/2019

Buono I, Formai S (2016) The evolution of the anchoring of inflation expectations. Bank of Italy Occasional Papers 321

Busetti F, Delle Monache D, Gerali A, Locarno A (2017) Trust, but verify. De-anchoring of inflation expectations under learning and heterogeneity. Working Paper Series 40.17. European Central Bank, pp 2259-2270

Calvo GA (1983) Staggered prices in a utility-maximizing framework. J Monet Econ 12(3):383-398

Capolongo A, Gros D (2019) The two-pillar strategy of the ECB: ready for a review. European parliament, monetary dialogue, December

Casas I, Fernández-Casal R (2019) tvReg: time-varying coeffcient linear regression for single and multiequations in R. SSRN Electron J

Casey E (2020) Do macroeconomic forecatsers use macroeconomics to forecast? Int J Forecast

Ciccarelli M, Osbat C (2017) Low inflation in the Euro area: causes and consequences. ECB Occasional Papers 181

Coibion O, Gorodnichenko Y (2015) Is the phillips curve alive and well after all? inflation expectations and the missing disinflation. Am Econ J Macroecon 197-232

Draeger L, Lamla MJ, Pfajfar D (2016) Are survey expectations theory-consistent? The role of central bank communication and news. Euro Econ Rev 85:84-111

Draghi M (2014) Unemployment in the Euro area. Speech at the annual central bank symposium in Jackson Hole, August 22

Draghi M (2016) How central banks meet the challenge of low in action. Marjolin Lecture, SUERF conference, Deutsche Bundesbank, Frankfurt

Ehrmann M, Jarociński M, Nickel C, Osbat C, Sokol A (2020) Inflation in a changing economic environment: insights from a conference at the ECB. https://voxeu.org/article/inflation-changing-econo mic-environment

Evans GW, McGough B (2018) Interest rate pegs in new Keynesian models. J Money Credit Bank 50:939-965

Evans G, Honkapohja S (2011) Learning as a rational foundation for macroeconomics and finance. CEPR discussion paper Series 8340

Fan J, Gijbels I (1996) Local polynomial modelling and its applications. Monographs on statistics and applied probability series 66. Chapman and Hall, London, pp XV-341

Fan J, Zhang W (2008) Statistical methods with varying coeffcient models. Stat Interface 1(1):179-195

Fendel R, Lis E, Rülke J-C (2011) Do professional forecasters believe in the Phillips curve? Evidence from the G7 countries. J Forecast 30(2):268-287

Fiedler S, Jannsen N, Stolzenburg U (2018) An economic recovery with little signs of inflation acceleration: transitory phenomenon or evidence of a structural change? In-depth analysis for the ECON Committee. European Parliament 
Fracasso A, Probo R (2017) When did inflation expectations in the Euro area de-anchor? Appl Econ Lett 24:1481-1485

Friedman M (1968) The role of monetary policy. Am Econ Rev 58(1):1-17

Galì J, Gertler M (1999) Inflations dynamics: a structural econometric analysis. J Monet Econ 44(2):195-222

García-Schmidt M, Woodford M (2019) Are low interest rates deflationary? A Paradox of perfect-foresight analysis. Am Econ Rev 109(1):86-120

Gobbi L, Mazzocchi R, Tamborini T (2018) Monetary policy, de-anchoring of inflation expectations, and the "new normal". J Macroecon 61:103070

Hall RE, Sargent TJ (2018) Short-run and long-run effects of Milton Friedman's presidential address. J Econ Perspect 32(1):121-134

Harvey AC, Phillips GDA (1982) The estimation of regression models with time-varying parameters. Games, economic dynamics, and time series analysis. Physica-Verlag HD, Heidelberg, pp 306-321

Hazell J, Juan H, Emi N, Jòn S (2020) The slope of the Phillips curve: evidence from U.S. States. NBER Working paper series 28005

Hooper P, Mishkin FS, Sufi A (2019) Prospects for inflation in a high pressure economy: is the Phillips curve dead or is it jus hibernating? NBER working paper series 25792

Jörgensen PL, Kevin JL (2019) Anchored inflation expectations and the flatter Phillips curve. Federal Reserve Bank of San Francisco, working paper series 2019-27

Jurado K, Ludvigson SC, Ng S (2015) Measuring uncertainty. Am Econ Rev 105(3):1177-1216

Kurz M (2011) Symposium: on the role of market beliefs in economic dynamics, an introduction. Econ Theory 8340:189-204

Lindé J, Trabandt M (2019) Resolving the missing deflation puzzle. In: CEPR Discussion Papers 2313690

Lucas RE (1973) Some international evidence on output-inflation tradeoffs. Am Econ Rev 63(3):326-334

Lyziak T, Paloviita M (2016) Anchoring of inflation expectations in the euro area: recent evidence based on survey data. ECB Working paper series 1945

Miccoli M, Neri S (2015) Inflation surprises and inflation expectations in the Euro area. Bank of Italy Occasional Papers 265

Nalewaik J (2016) Non-Linear Phillips curves with inflation regime-switching. Finance and economics discussion series 2016-078. Board of Governors of the Federal Reserve System, Washington

Natoli F, Sigalotti L (2017) Tail comovement in inflation expectations as an indicator of anchoring. Int J Central Bank

Nautz D, Laura P, Till S (2017) The (de-)anchoring of inflation expectations: new evidence from the euro area. North Am J Econ Finance 40:103-115

Nickel C, Bobeica E, Koester G, Lis E, Proqueddu M, Sarchi C (2019) Understanding low wage growth in the Euro area and European countries. ECB occasional paper 232

Paloviita M (2008) Comparing alternative Phillips curve specifications: European results with surveybased expectations. Appl Econ 40(17):2259-2270

European Parliament (2019) Task ahead: review of the ECB's Monetary Policy Strategy. Monetary Dialogue, December

Riggi M, Venditti F (2014) Surprise! Euro Area Inflation Has Fallen. Bank of Italy Occasional Papers 237

Riggi M, Venditti F (2015) Failing to forecast low inflation and Phillips curve instability: a euro-area perspective. Int Finance 18(1):47-67

Robinson PM (1989) Nonparametric estimation of time-varying parameters. Hackl P (ed) Statistical analysis and forecasting of economic structural change. Springer, Berlin, pp 253-264

Rülke J-C (2012) Do prefessional forecasters apply the Phillips curve and Okun's Law? Evidence from six Asian-pacific countries. Jpn World Econ 24(4):317-324

Oinonen S, Paloviita M (2014) Updating the Euro area Phillips curve: the slope has increased. Bank of Finland Research, Discussion Papers 31

Tucci MP (1995) Time-varying parameters: a critical introduction. Struct Change Econ Dyn 6(2):237-260

Williams J (2010) Sailing into headwinds: the uncertain outlook for the U.S. Economy. Technical Report 85, Reserve Bank of San Francisco

Woodford M (2003) Interest and prices. Princeton University Press, Princeton

Publisher's Note Springer Nature remains neutral with regard to jurisdictional claims in published maps and institutional affiliations. 